\title{
A THREE-DIMENSIONAL NUMERICAL MODEL OF THE RESPONSE OF THE AUSTRALIAN NORTH WEST SHELF TO TROPICAL CYCLONES
}

\author{
SONGPING ZHU' and JÖRG IMBERGER ${ }^{2}$
}

(Received 13 February 1992; revised 22 February 1993)

\begin{abstract}
A three-dimensional barotropic and baroclinic model is developed to simulate currents and temperature changes induced by tropical cyclones traversing the continental shelf and slope region of the Australian North West Shelf. The model is based on a layered, explicit, finite difference formulation using the nonlinear primitive equations with an embedded entrainment scheme; a mixed-surface-layer interface is defined, which is allowed to shift from one interface to another, depending on the strength of a storm. The model has been tested by simulating the currents and temperature changes induced by tropical cyclones Orson and Ian. The modelled currents and temperatures agreed well with the available measured records except near the seabed. It has been found that the pre-storm currents have very little influence on the peak of the storm-induced currents and the currents in the wake of a tropical cyclone. The model contained no coefficients which must be calibrated for a particular application and clearly illustrated the importance of the baroclinic effects on the storm-induced response over the North West Shelf of Australia.
\end{abstract}

\section{Introduction}

The North West Shelf (NWS) is a wide continental shelf region (Figure 1) characterised by strong tidal currents and often experiences tropical cyclones. The economic importance of this area to Australia is clearly recognised, primarily due to the availability of underlying natural gas and future production of both oil and gas. The design and construction of offshore oil and natural gas facilities require a knowledge of the currents in this region. This is particularly important on the NWS because large currents, both ambient and storm-induced, are common in this region. For this reason, modelling the response of the coastal and continental shelf water to tropical cyclones has been undertaken.

\footnotetext{
${ }^{1}$ Department of Mathematics, The University of Wollongong, Wollongong, NSW 2500, Australia

${ }^{2}$ Centre for Water Research, The University of Western Australia, Nedlands, WA 6009, Australia

(C) Australian Mathematical Society, 1994, Serial-fee code 0334-2700/94
} 


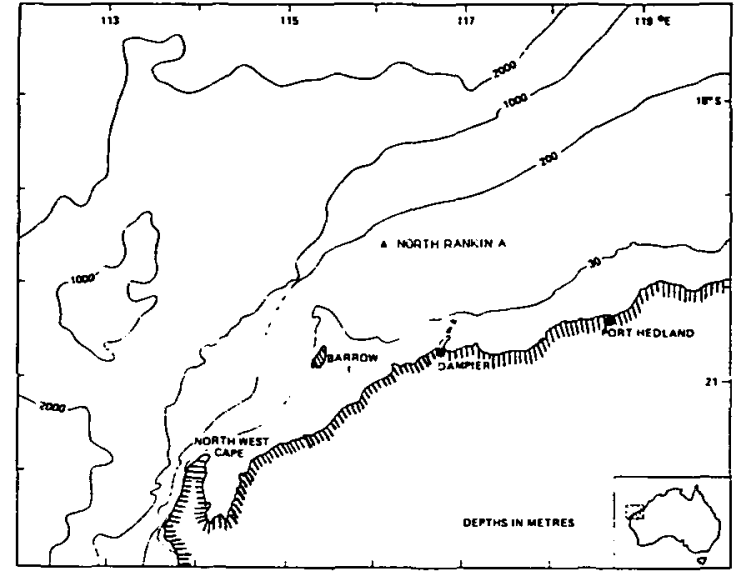

FIGURE 1. Map of Australian North West Shelf.

The response of the ocean to cyclone forcing has, in recent years, been investigated both by numerical modelling and with field measurements. Due to the extreme cost and difficulty of deploying enough instruments to resolve the ocean's response to a cyclone, numerical models have been emphasised and used to simulate such responses. However, most of these modelling efforts have focused on the deep ocean response far from the coast.

The steady-state response of a deep barotropic ocean of infinite extent to a hurricane moving with a constant speed was first studied analytically by Kajiura [27]. In a linear, inviscid, two-layer model, Geisler [12] derived an analytical solution for the horizontal structure of the vertical velocity field in the wake of a hurricane by convolving a Green's function with the wind stress curl. Among the numerical studies, O'Brien and Reid [36] and O'Brien [35] looked at the deep ocean baroclinic response to a stationary, axially-symmetric cyclone. They used the method of characteristics with a two-layer nonlinear model and found that the intense upwelling was confined to a region twice the radius of the maximum winds. With a turbulent kinetic energy budget parameterising the stress-induced vertical mixing, Chang and Anthes [3] investigated the ocean's nonlinear baroclinic response to a translating hurricane. They found that the ocean's response was greater on the right side of the storm track (in the northern hemisphere) and showed that vertical mixing produces significant differences in the depth of the thermocline behind the storm. Sea-surface-temperature (SST) response was studied by Price [41], using a three-layer model with vertical entrainment embedded between the mixed layer and the layer below. The model results were compared with data taken during the passage of the hurricane Eloise ([50]) and indicated that $85 \%$ of the irreversible heat flux into the mixed layer was caused by the vertical entrainment. Martin [32] also showed that the heat flux in the mixed layer was dominated by 
the entrainment for the first two inertial periods after eye passage. A multi-layer model with a wind mixed layer was introduced by Greatbatch [14] to study the baroclinic response of an open ocean to a moving cyclone. Nonlinearity was found to have a significant contribution to the current distribution as well as the maximum currents. The importance of studying the dynamic interaction between the barotropic and baroclinic modes was pointed out by Chang [2], who also provided a split-mode three-dimensional ocean model for the axially-symmetric response to a hurricane; however, he neglected the translation of the storm. All these previous deep-ocean modelling results revealed that Coriolis forces, convective acceleration and vertical entrainment are important in modelling the ocean response to a tropical cyclone.

The simulation of the water response over a continental shelf is made more difficult by the presence of the boundary conditions imposed at the coastline and at the shelf bottom. Kuo and Ichiye [29] developed a barotropic model to study the response of a regular constant-depth ocean with a shelf on one side. A sudden change of sea level and increase in water velocity were found to occur as the storm passes over the shelf. A two-layer barotropic and baroclinic model was presented by Suginohara [46]; considerable interface displacement along the typhoon track was found to be associated with the baroclinic mode. Forristall [10] developed a numerical model of winddriven currents, which incorporated a variable grid geometry and a two-layer density structure. However, his model did not predict the thermodynamic response. Cooper and Pearce [6] showed that the bottom shear stress plays a very important role in the response of the shelf water to a hurricane. Cooper and Thompson [7] developed a numerical model based on a layered, explicit, finite difference formulation to study the hurricane-generated currents on the outer continental shelf. Good agreement between the modelled and measured currents of hurricanes Frederic and Eloise indicated that the simulation of the turbulent mixing (see [41]) is critical for a baroclinic model. However, these authors had to use large bottom friction coefficients to overcome the difficulty that the second model layer generally disappeared at the shelf break, due to the intensive downwelling, within one inertial period after the passage of the storm. This work thus demonstrated the necessity of the further improvement of the entrainment scheme, which thus far had been only imposed on a single interface.

As an important first step in understanding the physical oceanography on the NWS and modelling of the response of the NWS to tropical cyclones, Imberger and Holloway [25] identified and described the basic features which constitute the flow over the NWS. These include barotropic tidal motion, low frequency (sub-inertial) wave motion, and tropical cyclone induced currents. The influence of tropical cyclones was first documented by Holloway et al. [23]. The oceanographic and meteorological data taken during the passage of cyclone Dean and cyclone Hazel were analysed. A mixed surface layer of 40 to $50 \mathrm{~m}$ deep was found immediately after cyclone Dean, together with strong barotropic and baroclinic currents. The influence of the bottom 
friction on shelf waves and circulations was examined by Webster $[48,49]$, who also suggested the appropriate range for the bottom friction parameter was between 0.025 and $0.05 \mathrm{~cm} \mathrm{~s}^{-1}$ for the NWS. Holloway and Nye [24] collected a large data set and correlated water currents, temperatures, sea levels, and meteorological data during and after the passage of a number of cyclones across the shelf. Temperature surveys indicated that the water was strongly stratified during the summer cyclone seasons. The analysis of twelve hour low-passed current data indicated that the most dramatic influence on the shelf water came from tropical cyclones; currents up to $1 \mathrm{~m} \mathrm{~s}^{-1}$ were recorded on the slope and shelf break region. However, only qualitative conclusions could be drawn from the limited data set available. Generally, slow moving and intense cyclones were found to induce a stronger response than fast moving and weak cyclones; currents were predominantly in the alongshore direction and to the southwest. The track of the cyclone was also found to be crucial to the response of the shelf water; cyclones moving parallel, but well away from the coast and cyclones moving perpendicular to the coast were found to generate strong responses over the shelf. Cyclones moving along and near the coast or slightly over the land were observed to produce only very weak responses.

The coastal geometry also has a strong influence on the nature of the response; quantitative simulations of the barotropic response of the NWS to tropical cyclones were carried out by Hearn and Holloway [16]. Utilising a $\sigma$-coordinate transformation, their three-dimensional barotropic model successfully modelled the sea level rises. However, for the strong baroclinic response induced during the summer cyclone seasons, poor results can be expected from a barotropic model. Cooper and Thompson [8] showed that the response of the hurricane-generated currents on the continental shelf in the Gulf of Mexico was primarily baroclinic (greater than $90 \%$ ). Both the structure of the currents across the width of the shelf and the existence of the downwelling (see [24]), as distinct from the upwelling which has been observed in the open ocean (for example, [41]), lead to the conclusion that the ocean response to a tropical cyclone moving over a shelf region is strongly baroclinic. On the other hand, Shay et al. [42] showed that the barotropic response associated with free-surface effects can contribute significantly at least within the first few inertial periods after the passage of a cyclone.

In this paper, we present a multi-layered barotropic and baroclinic model with the entrainment being allowed to shift from one interface to the next, according to a stability criterion. This new treatment of the turbulent mixing avoids not only the large currents near the storm centre predicted by other numerical models (for example, [10]), but also the need to use a large bottom friction coefficient in order to prevent two interfaces from approaching each other due to intensive downwelling (for example, [7]). In Section 2, the layered governing differential equations, initial and boundary conditions are presented. The turbulent mixing scheme and the parameterisation of the 
entrainment are then discussed. The numerical techniques for the spatial differencing and time integration are outlined in Section 3. Two test runs to simulate the ocean response to tropical cyclones Orson and Ian have been conducted; the results are compared with observations in Section 4. A summary is given in the final section.

\section{Model formulation}

2.1. Test basin and coordinate system We consider a rectangular ocean basin $(1500 \mathrm{~km}$ by $1500 \mathrm{~km})$ with a continental shelf and slope at the southeast coast and three other artificial boundaries on the remaining sides; this is a reasonable approximation to the North West Shelf, which has a generally straight coastline and a bottom with uniform slope in the alongshore direction. The mean cross section of the NWS was calculated from the available data and was used as the cross-section of the model test basin. A Cartesian coordinate system was adopted with $x$-axis pointing in the offshore direction, $z$-axis pointing upward and $y$-axis pointing in the alongshore direction to form a right-hand coordinate system. The origin of this local coordinate system is located at $\left(16.8^{\circ} \mathrm{S}, 125.8^{\circ} \mathrm{E}\right)$. The maximum depth of the basin at deep ocean was taken to be $4000 \mathrm{~m}$.

2.2. Governing differential equations The model was designed with $n$ layers of water with each pair being separated by a moving material interface. The layer thickness of the $k$-th layer is denoted by:

$$
D_{k}(x, y, t)=Z_{k}(x, y, t)-Z_{k+1}(x, y, t),
$$

where $Z_{k}(x, y, t)$ is the vertical position of the $k$-th interface as shown in Figure 2(a). The governing equations for a layered model were derived by Simon [43] and were modified slightly later by Zelt [52]. For easy reference, we rewrite them here.

If we take the basin width, $L_{0}$, as the horizontal length scale, the maximum depth of the seabed, $H_{0}$, as the vertical length scale, the density reference, $\rho_{0}$, as the density scale, $\sqrt{g H_{0}}$ ( $g$ is the gravitational acceleration), as the velocity scale, and $L_{0} / \sqrt{g H_{0}}$, as the time scale, the dimensionless equations of motion for the $k$-th layer, with the hydrostatic and Boussinesq approximations, can be written as:

$$
\begin{aligned}
& \frac{\partial D_{k}}{\partial t}=-\nabla \cdot\left(D_{k} \overrightarrow{\bar{v}}_{k}\right)-W_{e_{k}}+W_{e_{k+1}}, \\
& \frac{\partial D_{k} \bar{u}_{k}}{\partial t}=-\nabla \cdot\left(D_{k} \bar{u}_{k} \vec{v}_{k}\right)-\frac{\bar{p}_{k}}{\partial x}+\frac{1}{R} D_{k} \bar{v}_{k}-K_{v} \Delta\left(D_{k} \bar{u}_{k}\right) \\
& -\left(u W_{e}\right)_{k}+\left(u W_{e}\right)_{k+1}-\chi_{k}(u)+\chi_{k+1}(u), \\
& \frac{\partial D_{k} \bar{v}_{k}}{\partial t}=-\nabla \cdot\left(D_{k} \bar{v}_{k} \overrightarrow{\bar{v}}_{k}\right)-\frac{\bar{p}_{k}}{\partial y}+\frac{1}{R} D_{k} \bar{u}_{k}-K_{v} \Delta\left(D_{k} \bar{v}_{k}\right)
\end{aligned}
$$



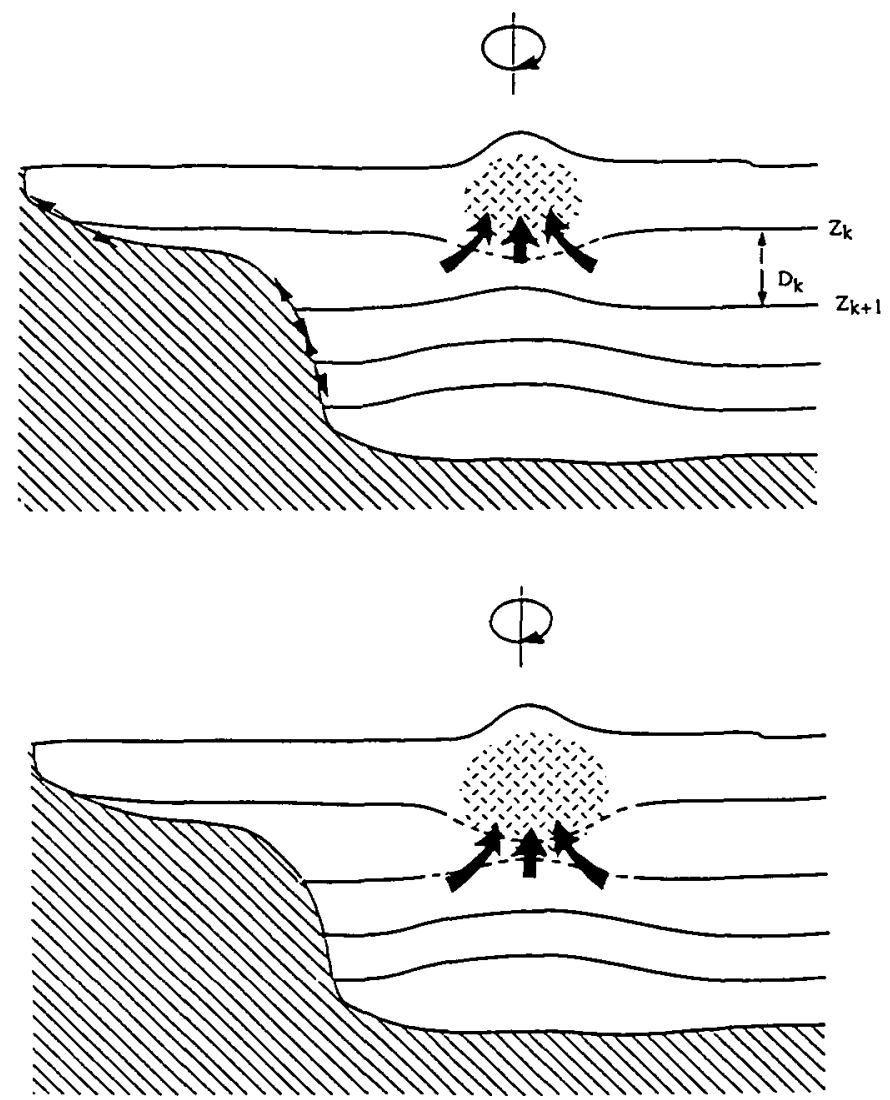

FIGURE 2. (a) An illustration of the multi-layered model and the structure of the interfaces used in the model. (b) An illustration of the shifting of the mixed-surface-layer interface.

$$
\begin{array}{r}
-\left(v W_{e}\right)_{k}+\left(v W_{e}\right)_{k+1}-\chi_{k}(v)+\chi_{k+1}(v) \\
\frac{\partial D_{k} \bar{T}_{k}}{\partial t}=-\nabla \cdot\left(D_{k} \bar{T}_{k} \vec{v}_{k}\right)-A_{v} \Delta\left(D_{k} T_{k}\right)-\left(T W_{e}\right)_{k}+\left(T W_{e}\right)_{k+1} \\
-\chi_{k}(T)+\chi_{k+1}(T),
\end{array}
$$

where $\nabla$ and $\Delta$ are the conventional horizontal gradient operator and Laplacian operator, respectively; $W_{e_{k}}$ is part of the volume transport per unit horizontal area across the $k$-th interface, i.e. the entrainment velocity, which will be parameterised in terms of Richardson number in the next subsection; $R_{0}$ is a Rossby number defined as

$$
R_{0}=\sqrt{g H_{0}} /\left(f_{0} L_{0}\right)
$$

with $f_{0}$ being the Coriolis parameter; $\vec{v}_{k}$ is the layer averaged horizontal velocity vector defined as

$$
\overrightarrow{\bar{v}}_{k}=\bar{u}_{k} \vec{i}+\bar{v}_{k} \vec{j}
$$


$\bar{T}_{k}$ is the layer averaged temperature; $\chi_{k}(u), \chi_{k}(v)$ and $\chi_{k}(T)$ are the stress flux in the $x, y$ direction and heat flux across the $k$-th interface, respectively. For any scalar quantity $\phi, \chi_{k}(\phi)$ is defined as

$$
\chi_{k}(\phi)=-\left.A_{\phi V} \frac{\partial \phi}{\partial z}\right|_{k}+2 A_{\phi H} \nabla \phi_{k} \cdot \nabla Z_{k}+A_{\phi V} \phi_{k} \Delta Z_{k}
$$

in which $A_{\phi V}$ and $A_{\phi H}$ represent appropriate eddy diffusivities corresponding to the variable $\phi$ (such as $u, v$ or $T$ ). Quantities without bars in (2) through (8) are the values of the corresponding quantities on the interfaces indexed by the subscript. As showed by Simon [43], putting

$$
\phi_{k}=\frac{1}{2}\left(\bar{\phi}_{k}+\bar{\phi}_{k+1}\right)
$$

i.e., the average from the two bounding layers of the $k$-th interface, is an appropriate choice for these quantities based on energy considerations. It is also a reasonable choice provided that the variable $\phi$ varies continuously through the water column. The average horizontal pressure gradient in layer $k$ can be obtained by integrating the vertical momentum equation to yield

$$
\nabla \bar{p}_{k}=D_{k}\left[\nabla p_{\mathrm{ext}}+\nabla p_{\mathrm{int}_{k}}+\left(\bar{\rho}_{k}-1\right) \nabla Z_{k}+\frac{1}{2} D_{k} \nabla\left(\bar{\rho}_{k}-1\right)\right],
$$

where

$$
p_{\mathrm{ext}}=p_{a}+\zeta,
$$

is the external pressure term which is the contribution to the pressure from both the imposed atmospheric pressure, $p_{a}$, and the elevation of the free surface, $\zeta$, above the mean sea level. This term will generate the barotropic motions, since it is layerindependent. Depending on the layer index $k$, the last three terms include the baroclinic forces experienced by the fluid in layer $k$. The term $p_{\text {int }}$ represents the internal pressure due to the density distribution above the $k$-th layer and is defined as,

$$
p_{\mathrm{ink}_{k}}= \begin{cases}0, & \text { for } k=1 ; \\ \sum_{i=1}^{k}\left(\bar{\rho}_{i}-1\right) D_{i}, & \text { for } k=2, \ldots, n,\end{cases}
$$

where $\bar{\rho}_{i}$ is the density of the water in the $i$-th layer and it is assumed to be a function of temperature only. The third term in (10) represents the force due to the tilting of the upper interface of layer $k$, and the fourth one represents the force due to the horizontal density gradient of the fluid within layer $k$.

The system will be closed if all the vertical mixing effects are related to the layeredmean variables $\bar{u}, \bar{v}$ and $\bar{T}$. That is, the turbulent entrainment must be parameterised so that the volume transport per unit horizontal area across the $k$-th interface, $W_{e_{k}}$, can be expressed by:

$$
W_{e_{k}}=W_{e_{k}}(\bar{u}, \bar{v}, \bar{T})
$$


Different choices of $W_{e_{k}}$ will result in different interface characteristics; Lagrangian interfaces correspond to $W_{e_{k}}$ being zero, whereas Eulerian interfaces will result where $W_{e_{k}}$ is such that $Z_{k}(x, y, t)$ is a constant. This flexibility allows easy introduction of the mixed-surface-layer interface at the base of the mixed surface layer. Across the mixed-surface-layer interface there is strong entrainment and below it the interfaces are essentially Lagrangian except for possibly weak diffusion.

\subsection{The vertical mixing and the entrainment laws A realistic simulation of the} ocean state near the centre of a storm is the key to a successful model since most of the storm induced current and temperature changes occur there. To simulate the turbulent mixing near the centre of a storm, we assume that the water entrained at the base of the surface layer is instantly mixed over the surface layer, and that momentum and heat are conserved in this mixing process. Various parameterisations of the vertical turbulent mixing have been used in modelling the ocean responses to tropical cyclones. Munk and Anderson [33] discussed earlier observations and presented a theory of thermocline formation which was based on the value of the Richardson number. O'Brien and Reid [36] parameterised vertical mixing by a quadratic friction formulation. Based on the work of Tennekes [47], Chang and Anthes [3] considered the energies of turbulent mixing in the mixed surface layer. Their entrainment scheme reduces to the same form as that proposed by Kato and Phillips [28]. Elsberry et al. [9] used a similar formulation except that the available turbulent energy had an exponential decay with depth. Spigel et al. [45] argued that both billow energetics and temporal effects should be taken into account in the turbulent kinetic energy budget. Taking the Richardson number as a scaling number for the turbulent entrainment was first suggested by Pollard et al. [39] and modified by Price [40]. This entrainment scheme, based on the bulk Richardson number of the mixed layer, was also utilised by Greatbatch [14]. The entrainment model of Price [40], which is used in the present model, is:

$$
W_{e}= \begin{cases}5 \times 10^{-4} R_{i}^{-4}|\delta \vec{V}| / \sqrt{g H_{0}}, & \text { if } R_{i} \leq 1 \\ 0, & \text { if } R_{i}>1\end{cases}
$$

where $W_{e}$ is the dimensionless entrainment velocity which is defined as the average flow of fluid per unit area normal to the interface, or the rate at which the position of the interface advances with time into the nonturbulent fluid. $R_{i}$ in (14) is the bulk Richardson number defined as:

$$
R_{i}=\frac{g \delta \rho H_{m}}{\rho_{0}|\delta \vec{V}|^{2}}
$$


in which $\delta \rho$ is the density difference, $\delta \vec{V}$ is the velocity difference across the base of the mixed surface layer and $H_{m}$, defined as

$$
H_{m}(t)=\sum_{i=1}^{K_{m}-1} D_{i}
$$

is the sum of the thicknesses of the layers above the mixed-surface-layer interface (with $K_{m}$ as the index of this interface), which will be defined in the following paragraphs. This parameterisation is based on the assumption that shear flow instability plays an important role in the vertical mixing, and has been strongly supported by several ocean modelling studies and field observations (for example, [41, 5]).

It has been long recognised that use of layered models with purely Lagrangian interfaces could result in numerical problems. For example, the interfaces may intersect, i.e. the layer thickness becomes zero due to either entrainment resulting from the strong turbulent mixing or the upwelling/downwelling of the thermocline resulting from the horizontal advection. For instance, when the cyclone winds blow over the ocean near a lateral boundary (the coast), it is possible for the isotherms to rise to the surface (or drop to the bottom). If purely Lagrangian interfaces are used, then these interfaces will be advected with the isotherms and they may surface as well, thus generating a region where interfaces can meet each other.

Similar problems can occur in the models with a mixed surface layer on top of a finite number of layers bounded by pure Lagrangian interfaces (see [41, 13, 7]). In all of these models, entrainment was assumed to take place only on the first interface immediately below the free surface. Problems arise when vigorous mixing forces the base of the surface layer down and the isotherms below are drawn up by the strong upwelling (illustrated in Figure 2(a)). Such behaviour is particularly prevalent when the cyclone centre approaches the coast where the water depth becomes less. Cooper and Thompson [7] used a large bottom friction coefficient, $c_{b}$, to retard the intensive downwelling of the interface near the shelf area.

In our model, an algorithm was developed to prevent two interfaces from approaching each other too closely; i.e. a minimum layer thickness, $\delta$, was specified. When this pre-set minimum layer thickness was reached, further reduction of the layer thickness was prevented; both interfaces subsequently move in tandem.

Three types of interfaces were defined. First, the interface immediately below the mixed surface layer (containing possibly numerous model interfaces) was identified, for convenience of later referral, as the mixed-surface-layer interface. This mixedsurface-layer interface, following the base of the mixed surface layer, may switch from one interface to another during the numerical experiment. Secondly, pure Lagrangian interfaces, across which no mass flux is allowed, were specified below the mixedsurface-layer interface. Thirdly, within the mixed surface layer, the interfaces were retained and used to reconstruct the density structure after the passage of the cyclone. 
Since all the fluid within the mixed surface layer was assumed to be fully mixed, these interfaces are then neither Eulerian nor Lagrangian; mass flux across these interfaces was set equal to the mass flux at the base of the mixed surface layer.

If two Lagrangian interfaces approached each other and the layer thickness between them reached the pre-set minimum layer thickness $\delta$, the layer thickness was then kept at $\delta$ until the two interfaces separated again by advection within the layer. Physically, this treatment corresponds to the concept that once a layer becomes too thin, the two interfaces that bound this layer should move as a single interface; all the physical quantities such as temperature and density are transferred across the thin layer. If the base of the mixed surface layer, on the other hand, approaches the adjacent Lagrangian interface, the mixed-surface-layer interface is shifted to the lower interface, and the entrainment law is imposed on the new mixed-surface-layer interface thereafter. The same amount of fluid was still assumed to flow across the interfaces now located above the mixed-surface-layer interface, and therefore the two interfaces moved virtually as one ([52]). This shifting process from the first interface below the free surface to the second interface is illustrated in Figures 2(a) and 2(b). Since the kinetic energy for mixing is mainly supplied by the current shear, $\delta \vec{V}$, which is induced by wind, this thickening of the mixed surface layer depends implicitly on the cyclone strength. Strong cyclones (low central pressure and strong wind) tend to make the mixed layer thicker. On the passage of the cyclone centre, the layer (or the layers) of minimum layer thickness residing within the mixed layer thickens by advection. The identifier for the mixed-surface-layer interface is then shifted back to the interface, below which the layer thickness had already been relaxed. This process not only allows the mixed layer to adjust its thickness according to the strength of the wind stress field, but also allows the recovery of the density structure after the passage of the cyclone as indicated by the observed field data. It is this shifting of the mixed-surface-layer interface that distinguishes our model from the models put forward by Price [41] and Cooper and Thompson [7].

2.4. Intersection of the interfaces with the seabed Since strong internal tides have been reported on the NWS by Holloway [19], especially on a shelf-break region where a large internal hydraulic jump was found (see [21, 22]), the intersection of the interfaces with the seabed should, in reality, move on the seabed as a consequence of the shoreward propagation of the internal waves (as indicated by the arrows on the seabed in Figure 2(a)). However, for computational convenience, the points of the intersection of the interfaces with the seabed were fixed in the model. This means that in a small region near these intersection points the interfaces are not fully Lagrangian; mass transport across the interfaces is allowed. This treatment may increase numerical diffusion and suppress the horizontal deformation of the interface in the alongshore direction as well; a large discrepancy between the modelled and measured currents 


\begin{tabular}{ccccc}
\hline \hline Layer & $\begin{array}{c}\text { Layer thickness } \\
\text { for Orson }(\mathrm{m})\end{array}$ & $\begin{array}{c}\text { Temperature } \\
\text { for Orson }\left({ }^{\circ} \mathrm{C}\right)\end{array}$ & $\begin{array}{c}\text { Layer thickness } \\
\text { for Ian }(\mathrm{m})\end{array}$ & $\begin{array}{c}\text { Temperature } \\
\text { for Ian }\left({ }^{\circ} \mathrm{C}\right)\end{array}$ \\
\hline 1 & 50 & 29.2 & 40 & 28.63 \\
2 & 30 & 28.2 & 30 & 26.0 \\
3 & 20 & 27.0 & 40 & 24.0 \\
4 & 30 & 24.0 & 20 & 20.0 \\
5 & 870 & 10.0 & 870 & 10.0 \\
6 & 3000 & 5.0 & 3000 & 5.0 \\
\hline
\end{tabular}

TABLE 1. The initial layer thickness and temperature profile used to simulate the response of the NWS to cyclone Orson and Ian.

near the shelf break has been generated as shown in the test runs, which will be discussed further in the following sections.

2.5. Initial conditions The initial velocity was assumed to be zero everywhere. In the simulation of the response of the shelf water to cyclones Orson and Ian, six layers were used. The total number of layers and the initial thickness of each layer were chosen in order to yield a reasonable resolution of the measured temperature profile prior to the storms Orson and Ian. The initial temperature distribution was taken from the mean temperature profile immediately before the cyclones. These initial ocean temperature data are presented in Table 1. All the physical coefficients used in the model for the simulation of the responses of the NWS to cyclones Orson and Ian are listed in Table 2. No attempt was made to use these coefficients to "tune" the model during the test runs. They were determined prior to the test runs according to either the standard value or those values popularly used in the literature. The horizontal eddy viscosity, for example, was chosen from Pedlosky [37]. The vertical eddy viscosity for the water on the NWS was determined according to Holloway [21].

2.6. Boundary conditions On the free surface, the wind stress and atmospheric pressure were applied at each time step. The wind stress and pressure were calculated from the wind model which will be discussed in Subsection 2.7. The heat exchange between the shelf water and the tropical cyclone was not considered in the present model. On the seabed, we used a linearised friction law

$$
\tau_{b x}=\left.\left[\rho c_{b} u\right]\right|_{z=-H}, \quad \tau_{b y}=\left.\left[\rho c_{b} v\right]\right|_{z=-H}
$$

where $\tau_{b x}$ and $\tau_{b y}$ are the bottom shear stresses and $c_{b}$ is a friction parameter, which is estimated according to Webster [49]. Since our average depth of the bottom layer was much smaller than the depth used in Webster's two-dimensional depth averaged model, our friction parameter, $c_{b}$, was chosen smaller than the lower bound given by 


\begin{tabular}{ccl}
\hline \hline Symbol & Value & \multicolumn{1}{c}{ Description } \\
\hline$C_{D}$ & $2.1 \times 10^{-3}$ & Wind friction parameter \\
$\rho_{a}$ & $1.15 \times 10^{-3} \mathrm{gm} \mathrm{cm}^{-3}$ & Air density \\
$p_{a}$ & $1008 \mathrm{hPa}$ for Orson; & \\
& $1006 \mathrm{hPa}$ for Ian & Ambient air pressure \\
$\beta$ & 1.83 for Orson, & \\
& 1.58 for Ian & Wind model parameter \\
$f_{0}$ & $-4.374 \times 10^{-5} \mathrm{~s}^{-1}$ & Coriolis parameter \\
$g$ & $9.8 \mathrm{~m} \mathrm{~s}^{-2}$ & Acceleration of gravity \\
$\alpha$ & $-3.3 \times 10^{-3}$ & Thermal expansion coefficient \\
$C_{b}$ & $0.01 \mathrm{~cm} \mathrm{~s}^{-1}$ & Bottom friction coefficient \\
$K_{H}$ & $5.0 \mathrm{~m}^{2} \mathrm{~s}^{-1}$ & Horizontal eddy diffusivity for momentum \\
$K_{V}$ & $1.0 \times 10^{-4} \mathrm{~m}^{2} \mathrm{~s}^{-1}$ & Vertical eddy diffusivity for momentum \\
$A_{H}$ & $5.0 \mathrm{~m}^{2} \mathrm{~s}^{-1}$ & Horizontal eddy diffusivity for temperature \\
$A_{V}$ & $1.0 \times 10^{-4} \mathrm{~m}^{2} \mathrm{~s}^{-1}$ & Vertical eddy diffusivity for temperature \\
\hline
\end{tabular}

TABLE 2. Values of physical constants and parameters.

Webster [49]. As far as the temperature field is concerned, the seabed was treated as an insulated boundary and therefore, the net heat flux was set to zero there. The specification of the lateral open boundary is very subtle. Zelt [52] suggested that the Sommerfeld radiation condition be applied on the open boundaries. However, it is very difficult to estimate the phase velocity on the open boundaries, at which any physical quantity propagates out of the domain. If grossly inaccurate values are used, very poor results can be expected. Thus, we chose the simple nonslip open boundary conditions,

$$
u=v=0 \quad \text { at } y=0, y=1500 \mathrm{~km} \text {, and } x=0,
$$

and this was applied to all the lateral boundaries except the northwest boundary $x=1500 \mathrm{~km}$, where a condition of zero flux normal to the boundary was applied together with the assumption that the sea level is in equilibrium with the atmospheric pressure. As indicated in the numerical work of Suginohara [46] and Kuo and Ichiye [29], the condition

$$
u=0 \text {, and } \zeta=\zeta_{0} \text { (static sea level) at } x=1500 \mathrm{~km} \text {, }
$$

will suppress the Kelvin waves, which may be generated at the northwest boundary. Since the northwest boundary was chosen to be far away from the shelf and shelf break, these waves were not considered in the present study. Our recently completed sensitivity tests of the model to the various open boundary conditions suggested by Chapman [4], including the Sommerfeld radiation condition, have shown that the domain chosen here was large enough to justify the land boundary conditions. 

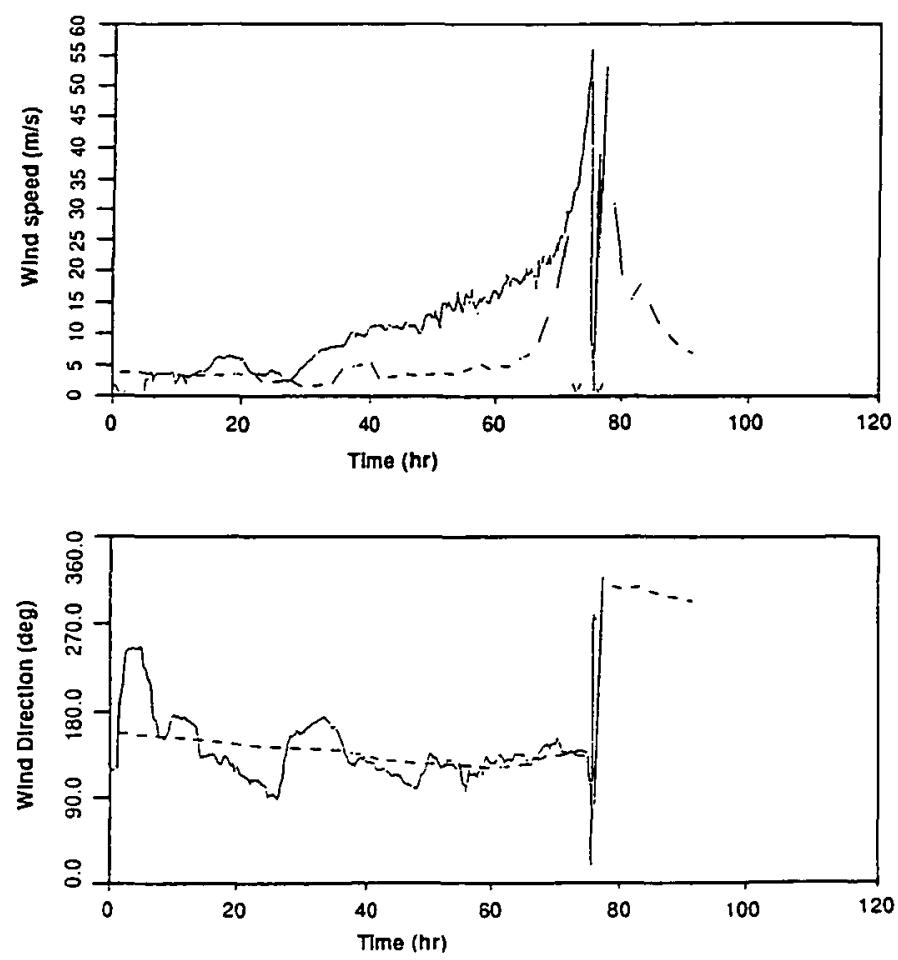

FIGURE 3. (a) The comparison of the modelled wind speed (dashed lines) and the measured one (solid lines) at NRA during the passage of cyclone Orson (supplied by Woodside).

(b) The comparison of the modelled wind direction (dashed lines) and the measured one (solid lines) at NRA during the passage of cyclone Orson (supplied by Woodside). The reference for wind direction is North.

2.7. The wind model The wind model used, which is based on that of Holland [18] and modified by Lovell et al. [30], had a radial pressure field given by

$$
p(r)=p_{e}+\Delta p \exp \left(-1 / \mu^{\beta}\right),
$$

where $p_{e}$ is the eye pressure of the cyclone; $\mu$ is the ratio of the radial distance, $r$, to the radius of the maximum winds, $R ; \Delta p$ is the pressure difference between the ambient air pressure, $p_{n}$, and the eye pressure, $p_{e}$. The associated wind profile was given by

$$
V_{\theta}=\left[\frac{\beta \Delta p}{\rho_{a} \mu^{\beta}} \exp \left(-1 / \mu^{\beta}\right)+\frac{1}{4} r^{2} f^{2}\right]^{1 / 2}-\frac{1}{2} f r,
$$

where $V_{\theta}$ is the tangential wind speed (in a reference frame moving with the storm) and $\rho_{a}$ is the density of air. The wind scale parameter, $\beta$, was estimated specifically for each particular storm. This empirical wind model is based upon a description of the wind and pressure field within the tropical cyclone, and does not attempt 

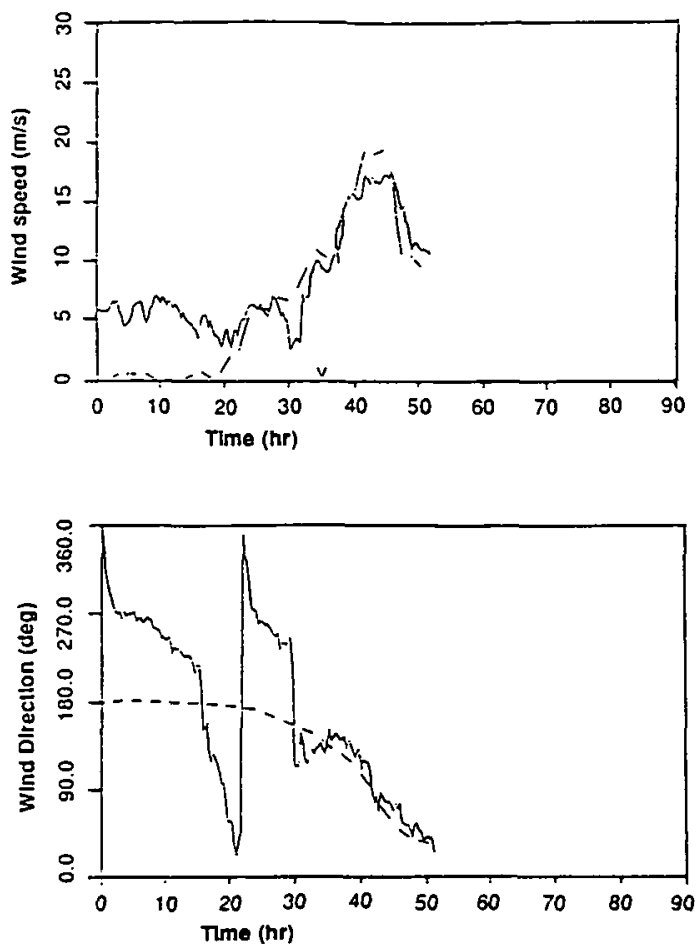

FIGURE 4. (a) The comparison of the modelled wind speed (dashed lines) and the measured one (solid lines) at Legendre Island during the passage of cyclone Ian (supplied by Woodside).

(b)The comparison of the modelled wind direction (dashed lines) and the measured one (solid lines) at Legendre Island during the passage of cyclone Ian (supplied by Woodside). The reference for wind direction is North.

to represent the influence of the synoptic, or regional, scale flow within which the tropical cyclone is moving. With the wind modelling concentrated on the peak of the storm, reasonably good agreement between the modelled and the observed wind speed and pressure around the peak when the cyclone dominates the synoptic field, were obtained. Figures 3(a), 3(b), 4(a) and 4(b), which were supplied by Woodside Offshore Petroleum Pty Ltd (Woodside), show the comparison of the wind model with the field measured wind data for cyclones Orson and Ian. Without cyclone inflow being taken into account in the wind profile, the wind model apparently showed larger errors prior to storm peak as shown in Figure 3(a). Further improvement of the wind model is certainly a key to developing a better ocean model.

The wind shear stress, $\vec{\tau}_{w}$, applied on the free surface of the ocean can be parameterised as:

$$
\vec{\tau}_{w}=\rho_{a} C_{D} V_{10}\left|\vec{V}_{10}\right|,
$$

where $V_{10}$ is the wind speed at a height of $10 \mathrm{~m}$ above the mean water level, and $C_{D}$ 
is a drag coefficient.

The main momentum exchange between the storm and the ocean is through the wind shear stress; the value of the drag coefficient, $C_{D}$, is thus critical. Various formulations of the surface drag coefficient have been proposed $([15,11,51])$, but a constant wind drag coefficient has most commonly been used in numerical simulation of the ocean's responses to tropical cyclones (for example, [36, 31, 29]). In the test runs of this study, the drag coefficient was chosen to be constant. The results of the ocean response to different formulations of wind drag coefficients will be presented in the sensitivity studies, which will be included in a forthcoming paper.

\section{Numerical procedures}

The layered governing (2) through (5) and the boundary conditions (18) and (19) were discretised on the staggered Arakawa $C$ grid ([1]) in space. Because of the assumption that the horizontal scale is much larger than the vertical scale, the grid points of each layer were fixed horizontally with respect to time. However, in the vertical direction, where the stratification may be nonuniform, the scales of the motion may also be nonuniform. To treat this inhomogeneity, the vertical coordinates of each lattice were allowed to change with the movement of the interface between layers. A uniform horizontal resolution in the $y$ direction was used, whereas nonuniform grids, in the $x$ direction, were generated automatically according to the mean bottom bathymetry. Sparse grids were distributed in the deep ocean to reduce computational time and denser grids were deployed near the coast in order to preserve a fine resolution near the current meter locations at North Rankin A (NRA). In the test run for cyclone Orson, $28 \times 35$ grid points were used, which covers $1500 \mathrm{~km}$ and $1500 \mathrm{~km}$ in the offshore and alongshore direction respectively. A high resolution grid, $48 \times 40$, was needed in the test run for cyclone Ian to compare the modelled results with the observed data due to the closeness of all the mooring sites as shown in Figure 5.

The choice of the time integration scheme for the numerical integration will greatly influence the accuracy, efficiency and stability of the calculations. The Lax-Wendroff explicit scheme ([44]) was found to be suitable for the derived layered partial differential equations. This scheme is efficient because it is a one-step method which requires only a single evaluation of the time derivative. It is also accurate to the second order of the time step $\Delta t$. As far as the numerical diffusion is concerned, Noye [34] compared the results from Gauss pulse tests for eight different finite difference schemes and found that Lax-Wendroff method was the best among all explicit schemes.

Since the layered finite difference equations on the discretised grids are very lengthy and have little to do with the theme of this paper, they are not included here.

As with other explicit schemes, there exists a stability criterion which restricts the 


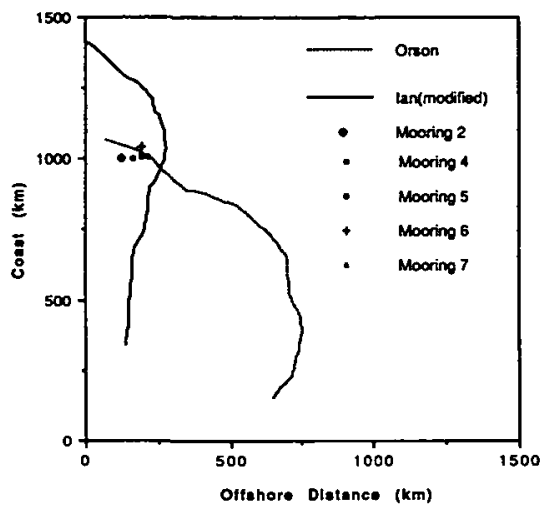

FIGURE 5. The storm tracks of cyclone Orson (dotted line) and cyclone Ian (solid line), and the positions of the mooring sites.

maximum time step allowed in the time integration. A rigorous stability analysis could not be given for equations of such complexity. Numerical experience indicated that the time step associated with any explicit scheme to solve equations governing wave propagation is limited by some form of the Courant-Friedrichs-Lewy (CFL) stability condition and stability criteria imposed by the diffusion terms [38]. For a reasonable range of the horizontal and vertical eddy diffusivity used in our simulation, the criterion imposed by CFL condition

$$
\Delta t \leq \frac{\Delta x_{\min }}{\sqrt{2 g H_{o}}}
$$

is the most restrictive. In (23), $\Delta x_{\min }$ is the minimum horizontal distance between two nodes; $\sqrt{2 g H_{o}}$ is the barotropic wave speed. Physically, imposing this condition implied that a wave must not propagate, within one time step, further than the distance to the next node. Although this condition limited the maximum time step of this explicit scheme, the choice of the explicit scheme was justified by the computational effort saved when including the entrainment algorithm.

\section{Results of the numerical experiments}

The responses of the NWS to moving cyclones may be conveniently divided into two stages. The first is the rapid response when the storm passes overhead and the second is the slow adjustment toward equilibrium in the wake of the storm. Since it is during the first stage when large currents are induced, the numerical integration in this study covers only the first stage, namely up to about one inertial period after the peak response. As indicated by the results of earlier field observation of the response of the shelf water to a number of cyclones on the NWS, the strength and the orientation of 
the track of the storm has the most significant influence on the induced ocean currents and temperature changes (see $[23,24]$ ). Therefore, the versatility of the model was evaluated by comparing the simulation results from two storms displaying different strengths and tracks. The numerical results were compared with the available field data recorded at a number of moorings deployed by Steedman Ltd on behalf of Woodside. Reasonably good agreement at most of mooring sites was obtained.

\subsection{Tropical cyclone Orson}

Background Tropical cyclone Orson was the most severe storm ever recorded in the NWS region, with an eye pressure of $905 \mathrm{hPa}$, a radius of maximum winds of $30 \mathrm{~km}$, and a translation speed of $8 \mathrm{~m} \mathrm{~s}^{-1}$. The storm passed directly over (within $4 \mathrm{~km}$ ) the NRA site (mooring 7 in Figure 5) on April 23, 1989, and moved almost perpendicular to the coastline as it approached the shore. The measured maximum 3-second gust wind speed adjusted to $10 \mathrm{~m} \mathrm{MSL}$ reference height was about $70 \mathrm{~m} \mathrm{~s}^{-1}$. During the passage of the cyclone, a mooring with three instruments at different water levels (7A, 7B and 7C) was deployed at NRA. Orson was an asymmetrical, well-defined storm. The numerical simulation was started on 20:00 April 19, 1989 when the storm centre was located at $\left(12.4^{\circ} \mathrm{S}, 121.0^{\circ} \mathrm{E}\right)$, or $(645.3 \mathrm{~km}, 150.9 \mathrm{~km})$ in the local coordinate system.

Comparisons and Discussion The offshore and alongshore velocity components and the temperature time history at the locations corresponding to the current meter and thermistor at NRA were computed by the model. Since the ambient currents on the NWS are strongly dominated by the principal lunar $\left(M_{2}\right)$ and principal solar $\left(S_{2}\right)$ tidal constituents, as discussed by Holloway $[20,21]$, current observations and simulation results as well as the temperature records were low-pass filtered. This removed the semi-diurnal and higher frequencies, but allowed the energy in the diurnal and lower frequencies of internal oscillations to remain. The mean currents, prior to the arrival of Orson, were also removed from the records. The comparisons of the modelled currents and temperatures at different depths with those from the field measurements are shown in Figure 6 through Figure 15.

Figure 6 shows the comparison of the modelled and the observed offshore currents at mooring $7 \mathrm{~A}$ ( $114 \mathrm{~m}$ above the seabed). The model predicted a peak offshore current of $0.40 \mathrm{~m} \mathrm{~s}^{-1}$, which is about $2.5 \%$ larger than the observed offshore peak current. The comparison of the alongshore components, in Figure 7, shows a 5\% error for the peak current induced. In the wake of the storm, an near-inertial oscillation with a period of 31 hours can be seen in both Figures 6 and 7; the damping of this oscillation seems to be quantitatively reproduced by the model. The near-inertial oscillation was also one of the predominant features in Shay et al.'s model ([42]). The large alongshore velocity component produced by the model and displayed by the field data agrees with 


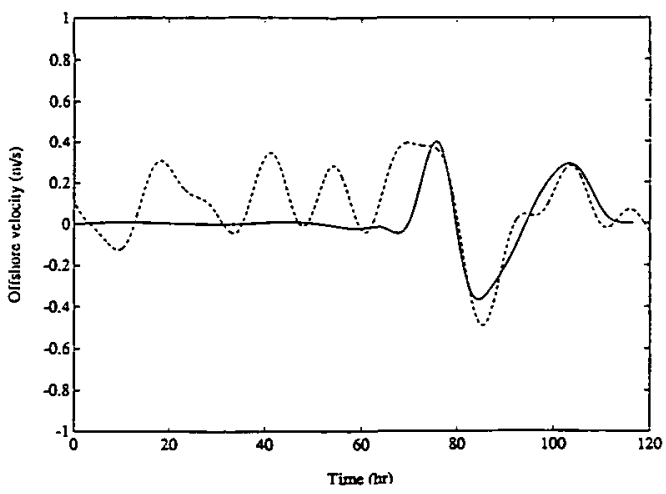

FIGURE 6. Comparison of the observed (dashed line) and modelled (solid line) offshore velocity components at mooring $7 \mathrm{~A}$ [10 m below MWS and located at $\left(19^{\circ} 25.1^{\prime} \mathrm{S}, 116^{\circ} 8.2^{\prime} \mathrm{E}\right)$ with total water depth $124.5 \mathrm{~m}]$.

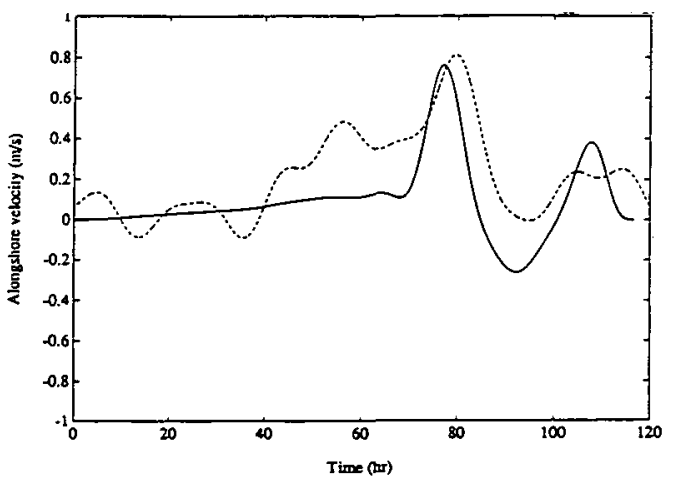

FIGURE 7. Comparison of the observed (dashed line) and modelled (solid line) alongshore velocity components at mooring $7 \mathrm{~A}$.

the qualitative observations by Holloway and Nye [24]. As expected, a comparison of Figure 3(a) with Figures 6 and 7 shows that the peak of the storm-induced current lags the peak of the wind speed for four hours. The faster the storm translates, the larger this phase lag will be. As will be shown later, for a much slowly moving storm, Ian, this phase lag disappeared.

A very prominent diurnal or near inertial oscillation of currents before the storminduced peak current was present in Figures 6 and 7 as well. The model was not expected to simulate these pre-storm oscillations. This was due to the adopted wind model, which did not represent the influence of the synoptic, or regional scale flow within which the tropical cyclone was moving, and the stationary initial conditions, which were certainly different from the ocean status prior to the arrival of Cyclone Orson. As can be clearly seen from Figure $3 \mathrm{a}$, there was very clearly a near-inertial oscillation in the wind field from the measured records. It might be this pre-storm oscillatory wind that induced the pre-storm currents. On the other hand, the modelled 
wind speed was very low (less than $5 \mathrm{~m} \mathrm{~s}^{-1}$ ) until the storm approached the NRA site. When the storm became dominant, the modelled wind matched fairly well with the measured one. Accordingly, the model performed well thereafter. This also shows that the storm-induced peak currents are strongly dependent on the local wind field within a tropical cyclone; the pre-storm currents have very little influence on the peak of the storm-induced currents and the currents in the wake of a tropical cyclone.

Figures 8 and 9 show the comparison of the modelled and observed offshorealongshore velocity components, respectively, corresponding to the current meter location at mooring 7B (59 m above the seabed). Again, at this lower current meter location, the model reproduced the storm induced currents with an error less than $3 \%$ of the peak measured currents in both offshore and alongshore directions. Large alongshore currents were also observed at NRA 55 hours prior to the cyclone-induced peak current. These large alongshore currents were possibly due to the background internal wave field naturally present in this part of the ocean. Holloway $[19,21]$ analysed the current and temperature data collected in this area and found that the ambient internal tides had predominantly semidiurnal periods. The currents associated with these internal tides could reach $0.2 \mathrm{~m} \mathrm{~s}^{-1}$. The field measurements at NRA showed that there were large internal waves prior to the arrival of cyclone Orson, with a 24-hour period, superposed on the dominant $M_{2}$ and $S_{2}$ internal tides. These internal waves were not induced by the storm as the storm travelled much faster than the phase speed of the fundamental mode of the internal waves. This may be seen by extracting the eigenfunction of the fundamental mode from the observed density structure. The maximum phase speed of these internal waves, according to the eigenfunction analysis, was $0.4 \mathrm{~m} \mathrm{~s}^{-1}$, which was much smaller than the translation speed of cyclone Orson. Therefore, they were not shown in the modelled records. Furthermore, due to the limited field records, the generation site of these low-frequency but large amplitude internal waves could not be located, and therefore, it was very difficult for them to be included as a boundary input.

Comparisons of each velocity component at mooring 7C (29 m above the seabed) are plotted in Figures 10 and 11 respectively; the alongshore component was badly in error. The large discrepancy resulted from internal wave sloshing of the fluid near the seabed. NRA is located near the shelf break, leading to internal waves sloshing up and down the sloping bottom. Since the thickness of sloshing is determined by the eigenfunctions corresponding to the internal wave modes, eigenfunction analysis showed that the current meter deployed at mooring 7C could have picked up the signals of the sloshing currents. On the other hand, this large shift of the interface on the seabed, due to the sloshing of fluid, was not accounted for in the model; all the interfaces in our model were pinned to the seabed at the location where they initially intersect the bottom. This was done, at this initial modelling stage of a complex problem, to avoid the difficulties associated with allowing the movement of 


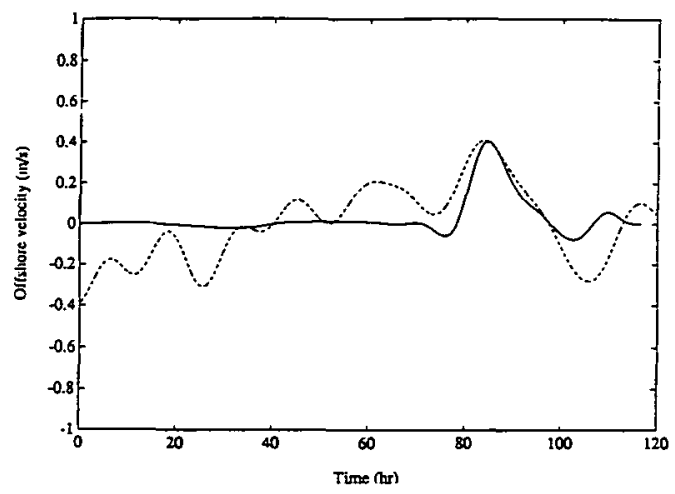

FIGURE 8. Comparison of the observed (dashed line) and modelled (solid line) offshore velocity components at mooring 7B[65 m below MWS and located at $\left(19^{\circ} 25.1^{\prime} \mathrm{S}, 116^{\circ} 8.2^{\prime} \mathrm{E}\right)$ with total water depth $124.5 \mathrm{~m}]$.

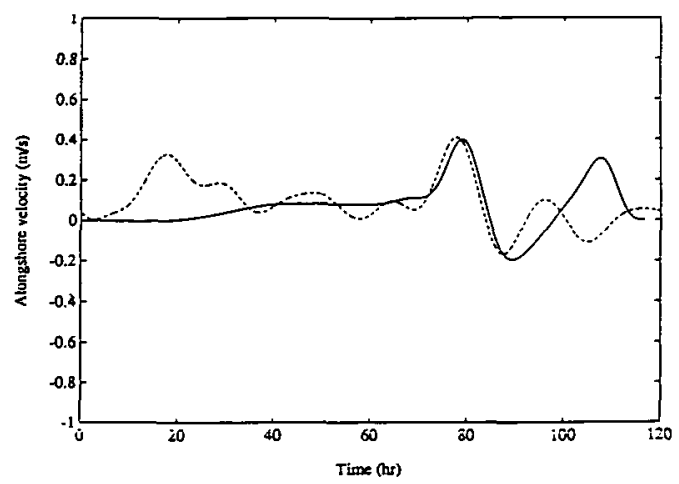

FIGURE 9. Comparison of the observed (dashed line) and modelled (solid line) alongshore velocity components at mooring $7 \mathrm{~B}$.

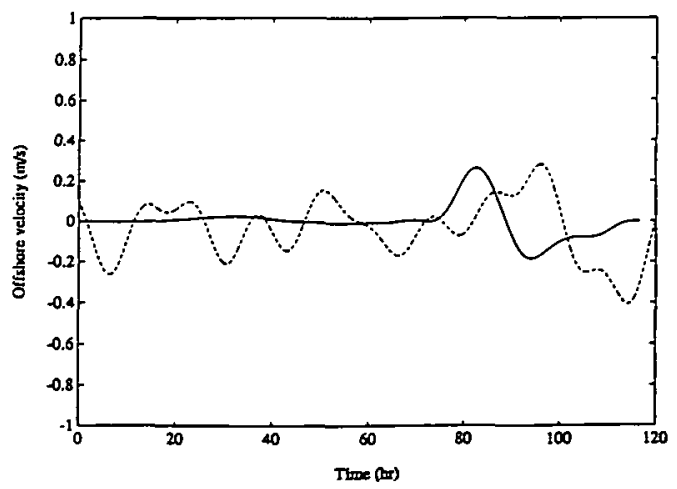

FIGURE 10. Comparison of the observed (dashed line) and modelled (solid line) offshore velocity components at mooring $7 \mathrm{C}$ [95 $\mathrm{m}$ below MWS and located at $\left(19^{\circ} 25.1^{\prime} \mathrm{S}, 116^{\circ} 8.2^{\prime} \mathrm{E}\right)$ with total water depth $124.5 \mathrm{~m}]$. 


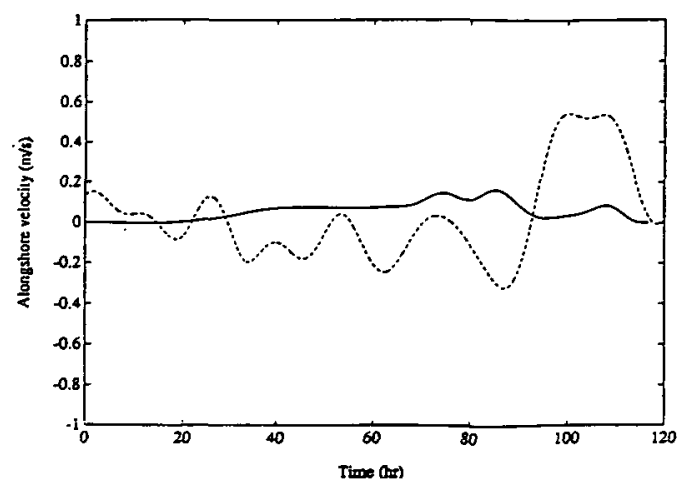

FIGURE 11. Comparison of the observed (dashed line) and modelled (solid line) alongshore velocity components at mooring $7 \mathrm{C}$.

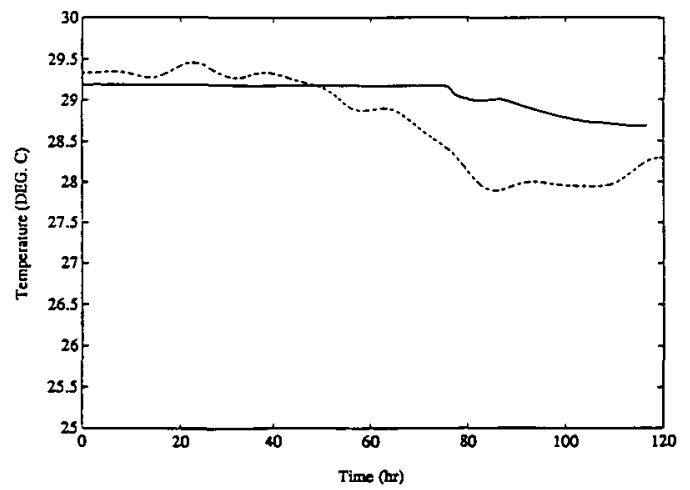

FIGURE 12. Comparison of the observed (dashed line) and modelled (solid line) temperature change at mooring $7 \mathrm{~A}$.

intersection points along the ocean floor. Clearly, this constraint also suppressed the pressure gradient, being built up in the alongshore direction; the modelled alongshore current was consequently much smaller than measured. The releasing of the pinned interfaces will be undertaken in the second phase of our modelling work.

Oscillations with the near-inertial period were found in the wake of the storm. These oscillations had already been shown by Greatbatch [13], and Hearn and Holloway [16]. However, in Hearn and Holloway's barotropic model, a small bottom friction coefficient had to be used to bring out the near-inertial oscillation in the wake of the storm. This had the effect of introducing a storm-induced current twice the observed magnitude. They argued that a solution to the "dilemma" was to alter the linear frictional law as presented in (17) to a generalised quadratic form as discussed by Hearn and Hunter [17]. The mixed barotropic and baroclinic model presented here does not suffer from this problem; the bottom frictional forces only influence the layer adjacent to the seabed. This can be clearly seen in Figure 11, where the oscillations 
of the velocity components are damped very rapidly by bottom friction.

The entrainment of fluid from the lower layer into the surface layer reduces the sea surface temperature (SST). The modelled temperature variation at mooring $7 \mathrm{~A}$ is compared, in Figure 12, with the observed data. In addition to having a phase lag, the model underestimated the temperature drop at this mooring by about $1.0^{\circ} \mathrm{C}$. This under-estimation of the temperature drop may have resulted from two approximations adopted in the model. First, the heat loss by evaporation and the sensible heat loss were ignored. Such heat exchange between the ocean and the atmosphere can reduce the temperature in the surface layer up to $34 \%$ of the total temperature drop according to Jordan's ([26]) estimation; but this accounts for only $0.34^{\circ} \mathrm{C}$ of the observed temperature decrease. A more likely explanation is the insufficient upwelling and the sensitivity of the response of the temperature field to the entrainment law parameters, and the prescribed critical Richardson number, at which the entrainment starts. As shown in Figure 14, the upwelling of the thermocline only reached up to about $28 \mathrm{~m}$ below the sea surface whereas the location of the thermometer $7 \mathrm{~A}$ was only $10 \mathrm{~m}$ deep. Improving the vertical circulation that brings the cold water up for more effective mixing necessitated the testing of other entrainment models such as those suggested by Kato and Phillips [28], and Spigel et al. [45], a task which is presently being undertaken. Another possible reason for the anomaly could be attributed to the delayed starting of upwelling in our model. The field data in Figure 12 shows that upwelling of the mixed-layer interface started as early as $t \approx 50 \mathrm{~h}$ (such an early thermocline disturbance can also been noticed in Figure 15). In the model, however, this process did not start until $t \approx 75 h$ as clearly indicated in Figure 14. This is mainly due to the insufficient wind stress supplied by the wind model prior to the arrival of the storm peak as shown in Figure 3(a).

Figure 13 shows the temperature change at the mid-depth (7B). A slight temperature rise before the main temperature drop is noticeable in the modelled records. This short-time temperature rise was due mainly to the downwelling of the surface-layer interface (see Figure 14), as it passed thermistor 7B initially located beneath this interface. Using a linear model, one can easily show that the variation of the interface is in phase with the density variation (see [21]). Since the density was assumed to vary linearly with the temperature in this study, we can expect an $180^{\circ}$ phase shift between the interface motion and the temperature variation. Although the velocity field is also related to internal progressive waves, the downwelling of the interface shown here was mainly due to the entrainment taking place at the base of the mixed surface layer. After the passage of the storm, the horizontal pressure gradient started to increase, which resulted in the main upwelling shown in Figure 14. As the upwelling prevailed, the temperature at $7 \mathrm{~B}$ started to drop. Similar variations were observed at the bottom mooring 7C as shown in Figure 15. At this mooring, large discrepancies were found during the period of the temperature rise; this is again due to the pinning 


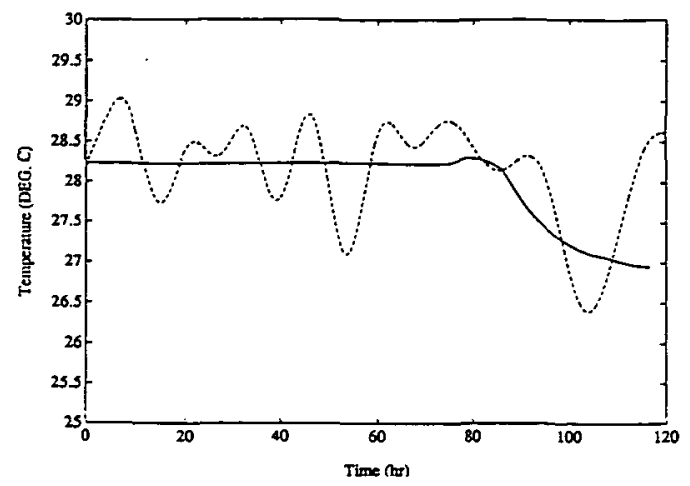

FIGURE 13. Comparison of the observed (dashed line) and modelled (solid line) temperature change at mooring $7 \mathrm{~B}$.

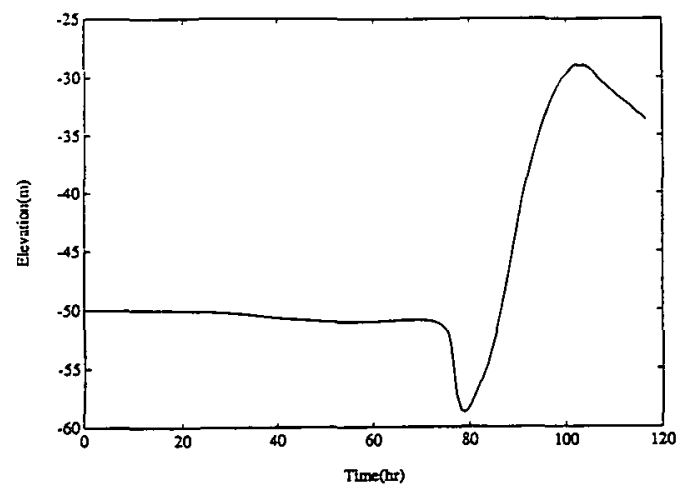

FIGURE 14. The temporal variation of the modelled surface-layer interfacial position at NRA during the passage of cyclone Orson.

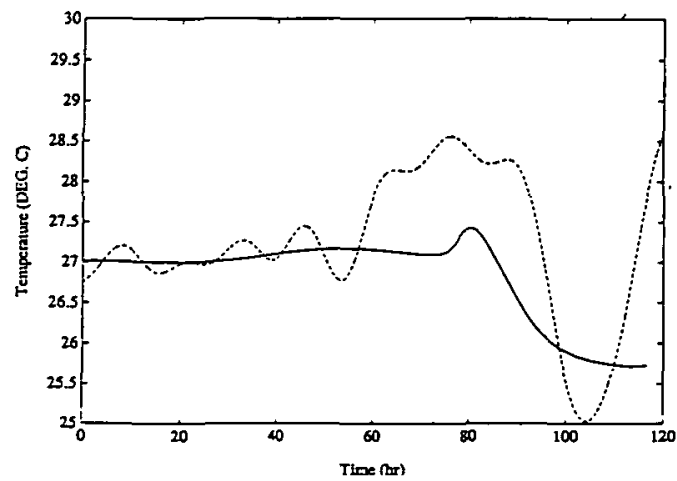

FIGURE 15. Comparison of the observed (dashed line) and modelled (solid line) temperature change at mooring $7 \mathrm{C}$. 


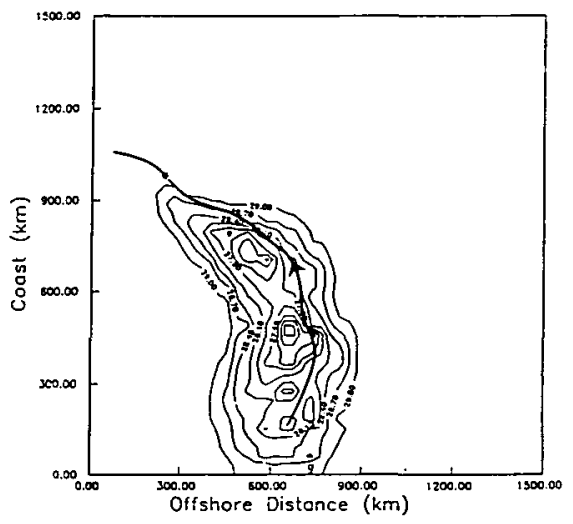

FIGURE 16. The sea surface temperature $\left({ }^{\circ} \mathrm{C}\right)$ distribution at 75 hours. The centre of the cyclone is indicated by the star $(*)$.

of the interfaces to the seabed.

The model-hindcast SST fields at 75 hours and 83 hours are plotted in Figures 16 and 17 respectively. The lowest SST at 75 hours was $26.56^{\circ} \mathrm{C}$, occurring at $50 \mathrm{~km}$ left of the storm track, and was $26.2^{\circ} \mathrm{C}$, at 83 hours occurring at $45 \mathrm{~km}$ left of the storm track. From both of these figures, one can see that the SST changed only in roughly a $500 \mathrm{~km}$ band along the track. In contrast to those models applied in the Gulf of Mexico (for example, $[41,7,8]$ ), this band was biased toward the left side of the storm track, which is a direct consequence of the asymmetry in the induced current field with currents to the left of the storm track more or less in phase with the wind stress field as clearly stated by Price [41] and Chang and Anthes [3]. In a two-layer baroclinic model with a stationary, axially-symmetric hurricane, O'Brien [35] found the upwelling was concentrated approximately within twice the radius of hurricaneforce winds. This confinement of the upwelling was also found from our model results. However, the upwelling disappeared after one inertial period. Downwelling was dominant in the wake of the storm after the storm centre had passed the site for more than one inertial period as can be clearly seen in Figure 18. Suginohara's ([46]) two-layer baroclinic model showed that typhoons caused considerable displacement of interfaces in the wake of the storm. This was also found in our model. For cyclone Orson, a maximum $50 \mathrm{~m}$ displacement of the surface layer interface was found in the wake of the storm, as shown in Figure 18. However, it should be noticed, once a fully developed wake had formed, there was very little change displayed in the temperature distribution. This behaviour of the upper layer in the wake of the storm was also reported in Suginohara [46], in which the pattern of the thermoclines did not change over 15 days after the passage of the typhoon.

Figures 19 and 20 show the sea surface elevation at 75 hours and 83 hours, respectively. At 75 hours, the maximum surge was about $0.45 \mathrm{~m}, 50 \mathrm{~km}$ away from the coast, while the storm centre was still about $248 \mathrm{~km}$ away from the coast. When the 


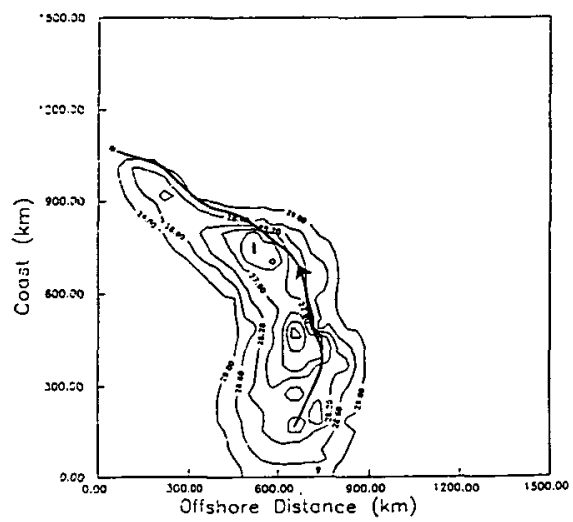

FIGURE 17. The sea surface temperature $\left({ }^{\circ} \mathrm{C}\right)$ distribution at 83 hours. The centre of the cyclone is indicated by the star $\left({ }^{*}\right)$.

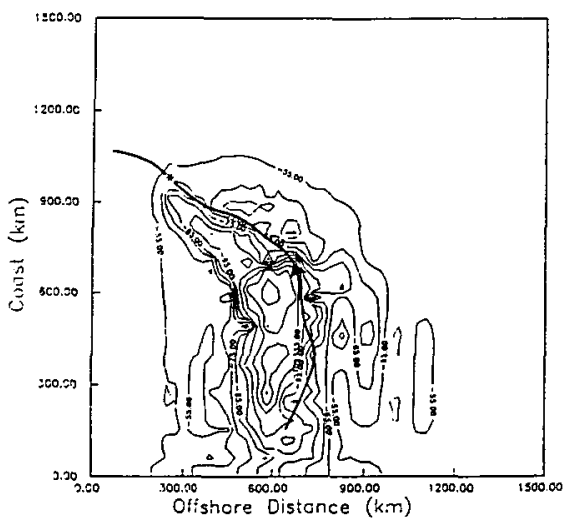

FIGURE 18. Depth $(\mathrm{m})$ of the first interface below the free surface at 75 hours. The centre of the cyclone is indicated by the star $(*)$.

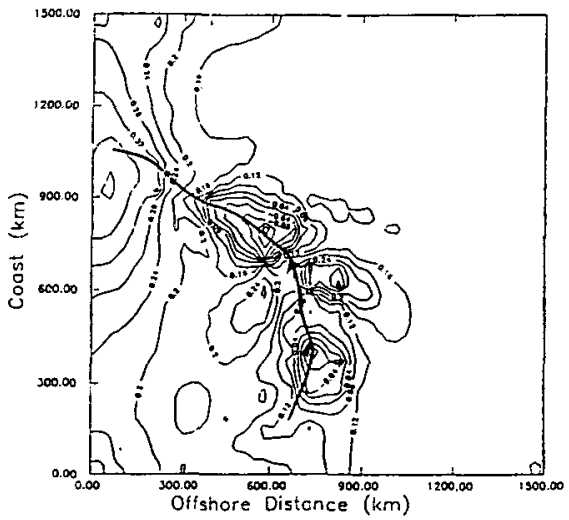

FIGURE 19. The sea surface elevation (m) at 75 hours. The centre of the cyclone is indicated by the star (*). 


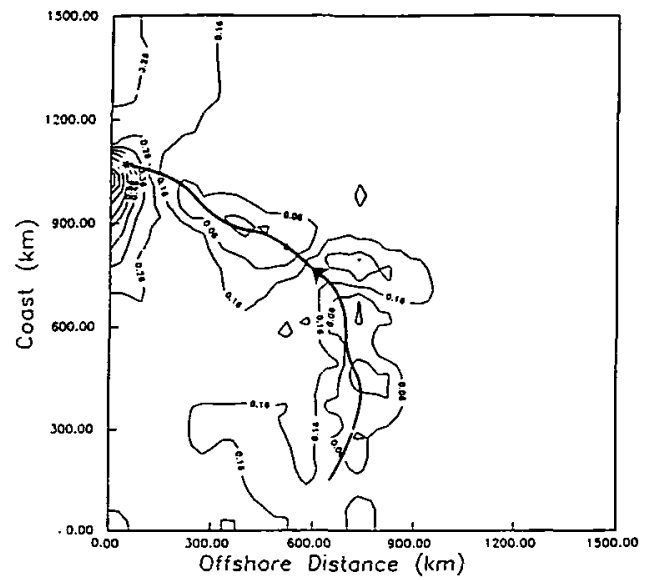

FIGURE 20. The sea surface elevation $(\mathrm{m})$ at 83 hours. The centre of the cyclone is indicated by the $\operatorname{star}\left({ }^{*}\right)$.

storm centre moved further toward the coast (about $48 \mathrm{~km}$ away from the coastline) at 83 hours, the maximum sea surface elevation reached about $1 \mathrm{~m}$. In the wake of the storm, the large range but small scale sea surface depression was followed by small range but large scale sea surface elevation as can be clearly seen in Figure 19; the sea surface depression formed a trough with a width of about $200 \mathrm{~km}$ along the track of the storm. This trough was created by the strong divergence. On the other hand, upwelling was always present near the storm centre for a fast moving storm such as Orson. This is due to the immediate dominance of the inverted barometric effect. As the wind stress forced the fluid to spin near the storm centre, the free surface started to fall as a consequence of the Ekman transport until a balance was achieved later between outward flow and the inward pressure gradient induced by the depression of the free surface.

A snapshot of the mixed-layer velocities at 75 hours is shown in Figure 21. Due to the asymmetric wind stress field adopted in the model, a remarkable across-track bias in currents were produced by Orson; the response on the left hand side of the track was much stronger than that on the right hand side. The intensification of the flow on the left hand side of the track shows that the position of an oil platform on the continental shelf relative to the storm track determines the effect of the cyclone on the platform. The strongly counter-clockwise rotating currents shown in Figure 21 were also observed by Church et al. [5] from their measurements during hurricane Gay.

\subsection{Tropical cyclone Ian}

Background Cyclone Ian was the most extensively documented NWS cyclone; a total of 11 current meters had been deployed by Woodside and three others had been deployed by West Australian Petroleum at Rosily. Ian reached peak intensity with 


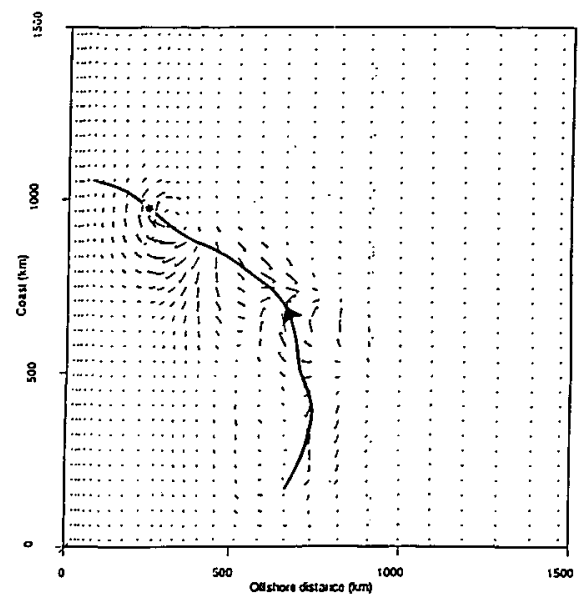

FIGURE 21. A snapshot of the mixed layer velocities at 83 hours after cyclone Orson starts at 20:00 pm 19 April, 1989 (Velocity scale: $1 \mathrm{~cm}=2.87 \mathrm{~m} \mathrm{~s}^{-1}$ ). The centre of the cyclone at this moment is indicated by the star $\left(^{*}\right)$.

an estimated eye pressure of $964 \mathrm{hPa}$ (the ambient pressure was $1006 \mathrm{hPa}$ ) and a maximum wind speed of $40 \mathrm{~m} \mathrm{~s}^{-1}$ on March 4, 1982. The storm track was almost parallel to the coast at $150-200 \mathrm{~km}$ offshore and the storm centre moved with a speed of about $4.5 \mathrm{~m} \mathrm{~s}^{-1}$. As discussed by Hearn and Holloway [16], the track of Ian supplied by the Bureau of Meteorology may have been in error by a few tens of $\mathrm{km}$. Therefore, the same modified track as used in Hearn and Holloway [16], shown in Figure 5, was adopted in this study. The simulation was started on 20:00, March 3, 1982 when the centre of cyclone Ian was located at $\left(17.2^{\circ} \mathrm{S}, 122.0^{\circ} \mathrm{E}\right)$, which corresponds to a local coordinate of $(137.4 \mathrm{~km}, 337.9 \mathrm{~km})$.

Comparisons and Discussion The initial setting of the layers and interfacial positions are given in Table 1. The initial temperature distribution was extracted from the field temperature records prior to Ian. The same low-pass filter as mentioned in Subsection 4.1 was again used for both the measured and model records. Further, the mean currents observed prior to the approach of cyclone Ian were removed from the measured records.

As shown in Figure 22, the model reproduced fairly well the offshore current induced by cyclone Ian at mooring $4 \mathrm{~A}$ except for about a 2 hour phase shift. The peak offshore current hindcast by our model was $0.22 \mathrm{~m} \mathrm{~s}^{-1}$ compared with the observed value of $0.21 \mathrm{~m} \mathrm{~s}^{-1}$. Figure 23 shows the comparison of the alongshore component at this mooring with a slightly larger error of the peak value; the modelled current overestimated the alongshore current at this current location by about $8 \%$.

As shown in Figure 5, moorings 5 and 6 were very close to each other and the total water depths at the corresponding locations were almost the same. Similar responses 


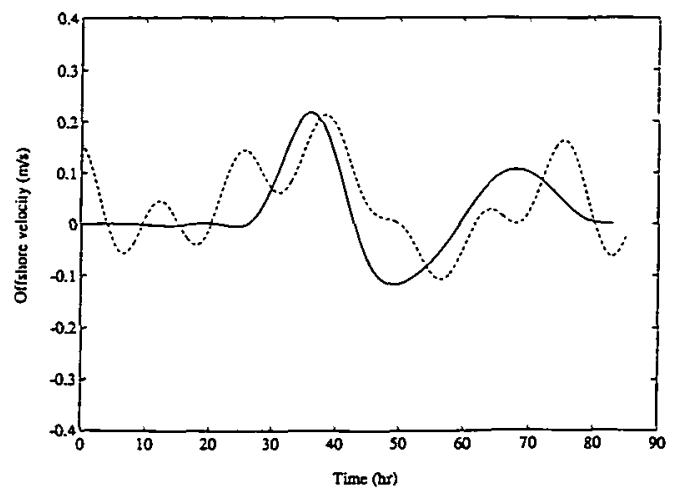

FIGURE 22. Comparison of the observed (dashed line) and modelled (solid line) offshore velocity components at mooring $4 \mathrm{~A}$ [ $21 \mathrm{~m}$ below MWS and located at $\left(19^{\circ} 58.6^{\prime} \mathrm{S}, 116^{\circ} 21.3^{\prime} \mathrm{E}\right)$ with total water depth $61 \mathrm{~m}]$.

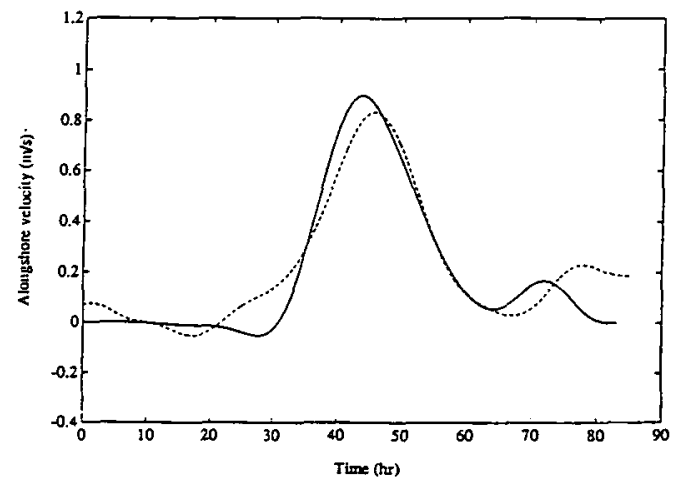

FIGURE 23. Comparison of the observed (dashed line) and modelled (solid line) alongshore velocity components at mooring $4 \mathrm{~A}$.

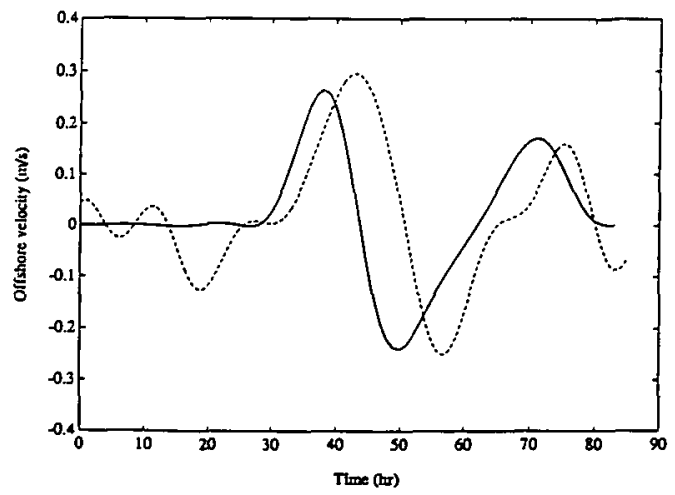

FIGURE 24. Comparison of the observed (dashed line) and modelled (solid line) offshore velocity components at mooring 6A [ $22 \mathrm{~m}$ below MWS and located at $\left(19^{\circ} 57.0^{\prime} \mathrm{S}, 115^{\circ} 56.2^{\prime} \mathrm{E}\right)$ with total water depth $72 \mathrm{~m}]$. 


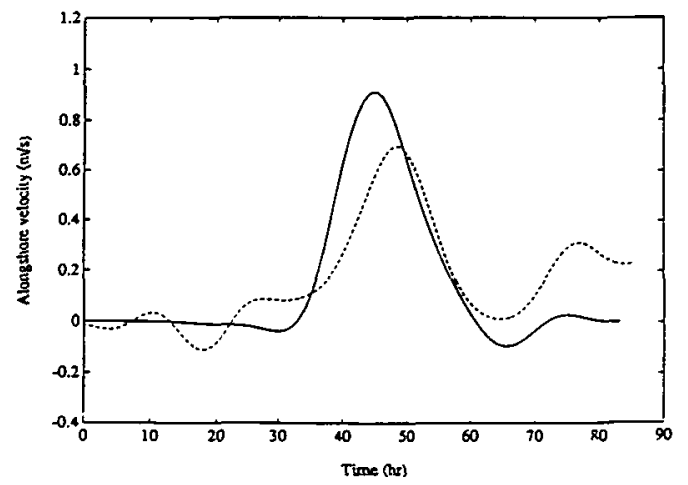

FIGURE 25. Comparison of the observed (dashed line) and modelled (solid line) alongshore velocity components at mooring $6 \mathrm{~A}$.

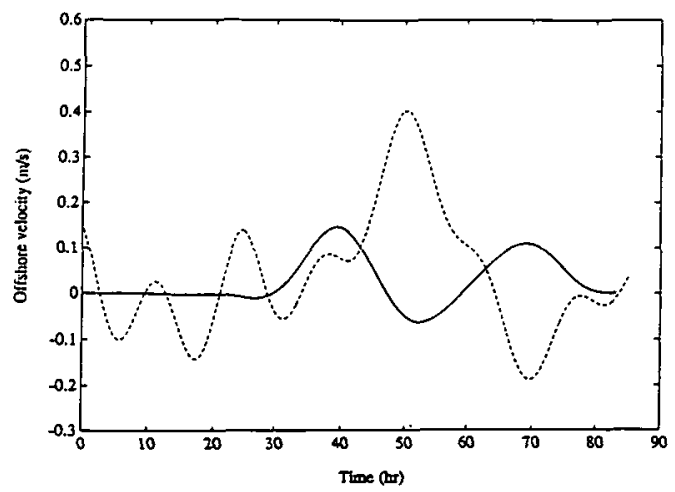

FIGURE 26. Comparison of the observed (dashed line) and modelled (solid line) offshore velocity components at mooring $6 \mathrm{~B}\left[52 \mathrm{~m}\right.$ below MWS and located at $\left(19^{\circ} 57.0^{\prime} \mathrm{S}, 115^{\circ} 56.2^{\prime} \mathrm{E}\right)$ with total water depth $72 \mathrm{~m}$ ].

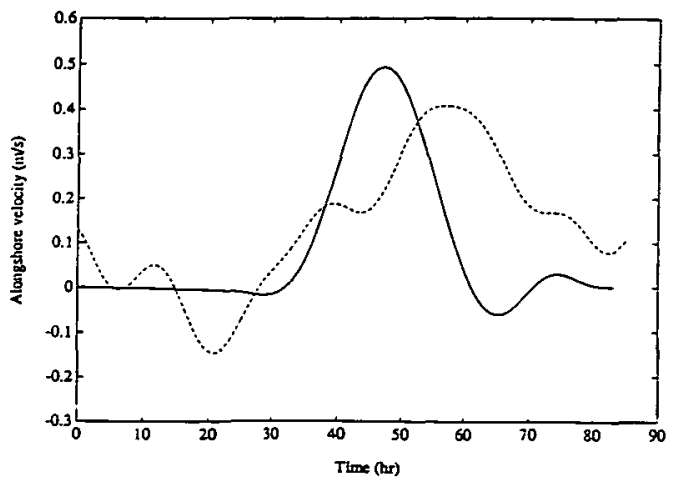

FIGURE 27. Comparison of the observed (dashed line) and modelled (solid line) alongshore velocity components at mooring $6 \mathrm{~B}$. 
of the four current meters, $5 \mathrm{~A}, 5 \mathrm{~B}, 6 \mathrm{~A}$ and $6 \mathrm{~B}$, at each mooring were indeed shown on both the field-measured and model-simulated record. Here, only the comparison at the mooring 6 is presented in Figures 24 through 27. As can be seen from Figure 24, at the top current meter $6 \mathrm{~A}$, which was located $50 \mathrm{~m}$ above the seabed, the model again well reproduced, apart from a small phase difference, the offshore current components. The peak alongshore components were over predicted by the model for approximately $0.25 \mathrm{~m} \mathrm{~s}^{-1}$ at mooring $6 \mathrm{~A}$ as shown in Figure 25. At the lower current meter locations $6 \mathrm{~B}$, in addition to a phase difference between the modelled and observed currents, the model did a very poor job in simulating the peak current induced by the storm as clearly shown in Figures 26 and 27 . This under-estimation may be directly related to the main mechanism of the momentum transfer in the model; a large portion of the momentum transfer depends on the downwelling of interfaces resulting from the entrainment of fluids from lower layers to upper layers. Ian was weaker than Orson; the energy supplied by the storm to mix fluid was much smaller and, consequently, the entrainment was not as strong as was observed in the wake of cyclone Orson. On the other hand, in the shallow water region where mooring 6 is located, the barotropic mode is dominant (see [7]), and the topographic friction flow is predominant as the wind stress is balanced by the bottom friction force. The momentum transfer from the surface Ekman layer to the layers close to the seabed is mainly through the shear stress; the increase of the vertical eddy diffusivity can increase the turbulent shear stress between the layers and thereby enhance the momentum diffusion from the top layer to the lower layers. This suggests that the vertical eddy diffusivity chosen for these test runs may not be versatile enough to cover the cases such as simulating the response to a weak storm or the flow in very shallow water. Adding more layers locally in this region would have helped to better resolve the baroclinic structure, but a localised imbedding would have been numerically very complicated and a uniform increase in the number of layers throughout the whole domain would have been computationally too expensive.

The comparisons of the modelled and the measured temperature changes at thermistor locations 4A, 6A and 6B are shown in Figures 28 through 30. Except for the modelled temperature drop at $4 \mathrm{~A}$ being about $0.4^{\circ} \mathrm{C}$ less than the observed, the model seems to reproduce well the trend of both the temperature drops at $4 \mathrm{~A}$ and $6 \mathrm{~A}$. The temperature rise of the modelled record at the lower thermistor locations $6 \mathrm{~B}$, as shown in Figure 30, was mainly due to the downwelling of the thermocline. However, there was a temperature drop measured at thermistor location $6 \mathrm{~B}$ after the storm induced temperature rise. The model did not follow the trend of this temperature drop, which was possibly due to the modified track, in the model simulation, being shifted too far away from mooring 6 so that not enough wind energy was supplied to the water column for intensive mixing right after the storm centre had passed the mooring location. 


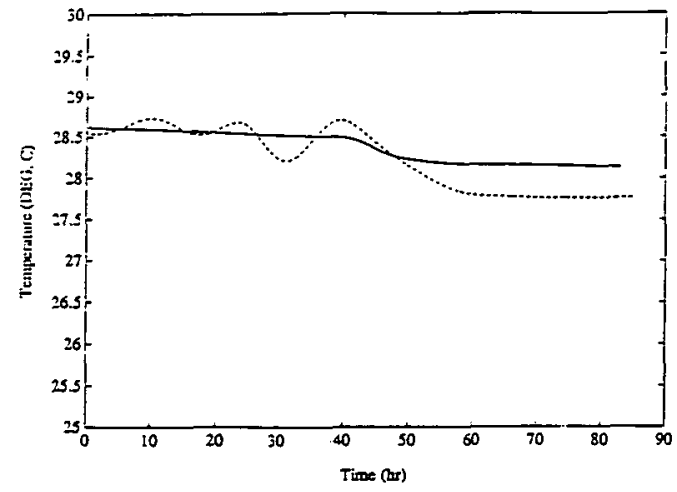

FIGURE 28. Comparison of the observed (dashed line) and modelled (solid line) temperature change at mooring $4 \mathrm{~A}$.

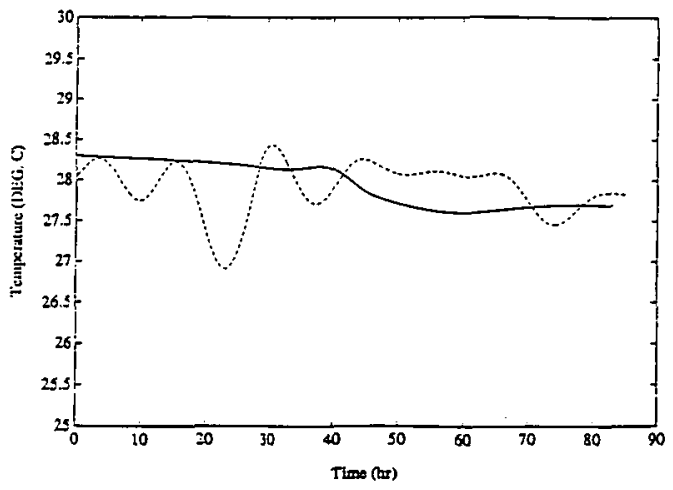

FIGURE 29. Comparison of the observed (dashed line) and modelled (solid line) temperature change at mooring $6 \mathrm{~A}$.

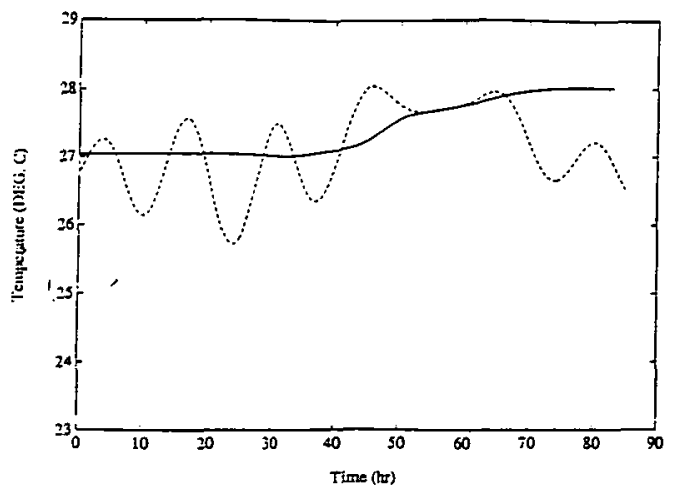

FIGURE 30. Comparison of the observed (dashed line) and modelled (solid line) temperature change at mooring $6 \mathrm{~B}$. 


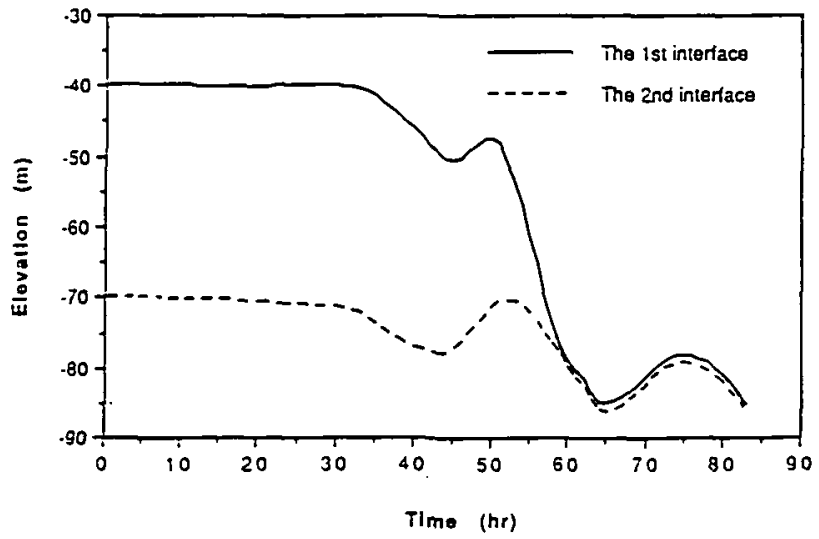

FIGURE 31. The temporal variation of the position of the modelled first and the second interfaces at NRA during the passage of cyclone Ian.

At the shelf break (mooring 7), a well mixed surface layer of about $80 \mathrm{~m}$ thickness was found from our model. This can be seen from the temporal variation of the interfaces shown in Figure 31, in which the interfacial positions of the first and the second interfaces below the free surface are plotted respectively. When the entrainment started through the first interface at about 35 hours after the simulation began, the downwelling of the first interface induced, due to the deformation of the interface, an internal pressure gradient, which set off an near-inertial oscillation of the second interface. The mixed surface layer was further deepened as the downwelling of the first interface continued. At about 60 hours, the minimum layer thickness of the second layer was reached and the mixed-surface-layer interface was switched to the second interface. Once the centre of the storm had passed the site, the relaxation began and these interfaces started to oscillate in the wake of the storm.

Finally, to compare the flow pattern induced by cyclone Ian, which is of a track parallel to the coastline, with the flow pattern induced by a cyclone with a perpendicular track to the coastline such as Orson, a snapshot of the surface layer velocity at 50 hours is shown in Figure 32. Again, the strong responses were found on the left hand side of the storm, but were mainly trapped on the continental shelf. Taking into consideration that the wind strength (maximum wind and eye pressure difference with respect to the ambient pressure) of cyclone Ian was much weaker than that of Orson, and the current responses were only slightly weaker than those induced by Orson, one can conclude that cyclones with a parallel track to the coast will produce stronger responses than those moving with a track perpendicular to the coast, had other conditions been kept the same. This is because the existence of the coastline, as a boundary, forces the flow to be parallel to it, and this alongshore component is again amplified by the wind stress, which is now almost parallel to the coast on the left hand of the track and in the same alongshore direction. Due to the intensified alongshore currents and the slow 


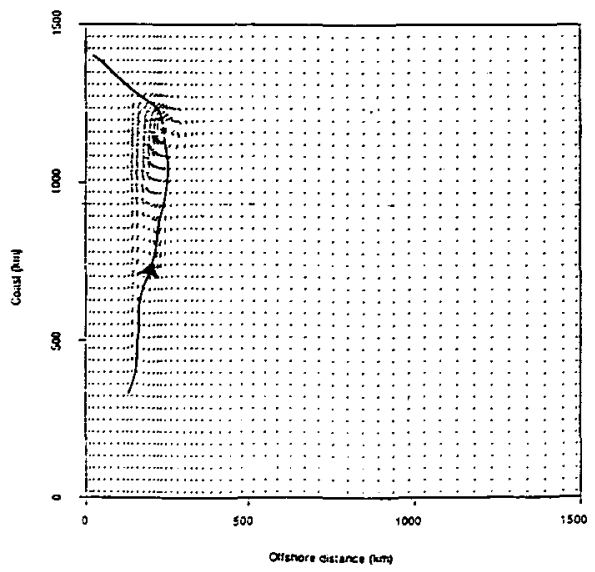

FIGURE 32. A snapshot of the mixed layer velocities 50 hours after cyclone Ian starts at 20:00 pm 3 March, 1982 (Velocity scale: $1 \mathrm{~cm}=2.47 \mathrm{~m} \mathrm{~s}^{-1}$ ). The centre of the cyclone at this moment is indicated by the $\operatorname{star}(*)$.

translation speed of the storm centre (compared with the translation speed of cyclone Orson), large storm-induced currents can be felt even before the storm centre arrives. This contrasts with the response of the shelf water to tropical cyclone Orson as shown in Figure 21, where the storm-generated response seems to be much larger in the wake of the storm.

\section{Conclusion and summary}

This study focused on the development of a three-dimensional barotropic and baroclinic numerical model to simulate the Australian North West Shelf response to tropical cyclones. The model presented here used a layered, explicit finite difference formulation. A turbulent entrainment and mixing scheme was embedded in the layered model to simulate the surface dynamics. A distinguishing feature of our model is that the mixed-surface-layer interface was allowed to shift from one interface to another according to the strength of a storm. This treatment properly simulated the entrainment and mixing in the wake of the storm, when the downwelling of the mixed-surfacelayer interface was so large that it approached the interface below. A minimum layer thickness was set so that, when this minimum layer thickness between the two approaching interfaces was reached during the numerical integration, the mixedsurface-layer interface was shifted to the next interface down, and the two interfaces were then treated as one until later horizontal advection once again separated them.

The model results were compared with field-observed responses for two particular storms, tropical cyclones Orson and Ian, the tracks of which were perpendicular and parallel to the coast, respectively. No attempt was made to "tune" or "optimise" the 
model output, yet the model reproduced reasonably well the barotropic and baroclinic responses of the shelf water to the two test cyclones, apart from less satisfactory results for the near-seabed ocean currents and temperature. Although our present studies focused on the simulation of the peak current and the storm-induced current and temperature response within one inertial period, the model has shown that the turbulent entrainment and mixing are very important processes in the wake of a storm. However, in the shallow water region, the momentum diffusion resulted from large turbulent shear stress played an equally important role when the barotropic mode is dominant.

The wind model adopted in the simulation only represents the wind and pressure field within the tropical cyclones, and does not attempt to represent the influence of the synoptic scale flow within which the storms are moving. However, our preliminary results showed that pre-storm currents have very little to do with the peak of the storm-induced currents and the currents in the wake of a tropical cyclone.

The sea surface temperature drop in the surface layer and the temperature rise of the lower moorings observed during the passage of the cyclones were reproduced reasonably well by the model. The temperature changes were closely linked to the upwelling and downwelling of the interfaces, which were mainly caused by the entrainment and mixing of the fluids near the storm centre and in the wake of a storm. Considerable displacement of the mixed-surface-layer interface was found in the wake of the storm. The disturbed density stratification and interfacial positions in the wake of a storm remained for quite a long time.

The orientation of the storm track relative to the coast was shown to have a large influence on the responses of the shelf water. The cyclones with the track parallel to the coastline induce larger responses compared with those with the track perpendicular to the coast. This has been verified by the results of our sensitivity test (these results and detailed discussion will be published in a forthcoming paper); the alongshore velocity component was nearly doubled as the storm track varied from perpendicular to parallel to the coast if other parameters and the strength of the storm were kept constant. Furthermore, the baroclinic structure of the induced current in the NWS region was clearly demonstrated by these sensitivity tests as there was a $180^{\circ}$ phase shift between the top current meter records and the bottom current meter records at NRA when the storm track formed a right angle with respect to the coastline.

Despite its success thus far, there are several drawbacks to the model, which needs to be further improved. The model-simulated responses at locations close to the seabed were not as good as those away from the ocean floor. This was due to all the interfaces being pinned on the seabed during the numerical integration. In order to simulate the sloshing of the shelf water near the seabed, fully Lagrangian interfaces must be adopted near the points where the interfaces intersect the sea floor. The release of the interfaces at these intersecting points would however involve substantial programming effort and 
would certainly increase the computational time unless a curvilinear coordinate system (such as $\sigma$-coordinate) was adopted. The inclusion of the tidal currents and internal tide is also necessary to study the nonlinear interaction between the cyclone induced response and the ambient flow dominated by semidiurnal tidal constituents.

\section{Acknowledgement}

The authors wish to thank the Joint Venture Participants and the management of Woodside Offshore Petroleum Pty Ltd for permission to present this paper.

The participants in the North West Shelf Joint Venture are Woodside Petroleum Ltd (through subsidiaries), Shell Development (Australia) Proprietary Limited, BHP Petroleum (North West Shelf) Pty Ltd, BP Developments Australia Limited, Chevron Asiatic Limited and Japan Australia LNG (MIMI) Pty Ltd.

We are very grateful to Dr Jeff Zelt, who formed the foundation of this work during a two-year post-doctoral fellowship at the Centre for Water Research. We also like to express our gratitude to Dr Peter Holloway, who provided valuable data on cyclone Ian with the permission from Woodside Offshore Petroleum Pty Ltd. Our appreciation is extended to Dr Bruce Harper, who, on behalf of Woodside Petroleum, supplied the wind model, the calibration storm parameters and Figures 3 and 4 in this paper, and to Dr Andrew Barry, who gave valuable comments on the manuscript. Finally, our thanks go to Mr Steve Buchan, who organised the transfers of the Woodside field measured data of cyclone Orson to the Centre for Water Research and to one of the reviewers, who made a very extensive review and made some very valuable comments on the manuscript.

\section{References}

[1] A. Arakawa and V. R. Lamb, "Computational design of the basic dynamical processes of the UCLA general circulation model”, Methods in Comp. Phys. 17 (1977) 173-265.

[2] S. W. Chang, "Deep ocean response to hurricanes as revealed by an ocean model with free surface", J. Phys. Oceanogr. 15 (1985) 1847-1858.

[3] S. W. Chang and R. A. Anthes, "Numerical simulations of the ocean's nonlinear, baroclinic response to translating hurricanes", J. Phys. Oceanogr. 8 (1978) 468-480.

[4] D. C. Chapman, "Numerical treatment of cross-shelf open boundaries in a barotropic coastal ocean model", J. Phys. Oceanogr. 15 (1985) 1060-1075.

[5] J. A. Church, T. M. Joyce and J. F. Price, "Current and density observation across the wake of Hurricane Gay", J. Phys. Oceanogr. 19 (1989) 259-265.

[6] C. Cooper and B. Pearce, "Numerical simulations of hurricane-generated currents", J. Phys. Oceanogr. 12 (1982) 1071-1091.

[7] C. Cooper and J. D. Thompson, "Hurricane-generated currents on the outer continental shelf. Part 1", J. Geophy. Research 94 (1989) 12513-12539. 
[8] C. Cooper and J. D. Thompson, "Hurricane-generated currents on the outer continental shelf. Part 2", J. Geophy. Research 94 (1989) 12540-12554.

[9] R. T. Elsberry, T. Fraim and R. Trapnell Jr., "A mixed layer model of the oceanic thermal response to hurricane", J. Geophy. Research 81 (1976) 1153-1162.

[10] G. Z. Forristall, "A two-layer model for hurricane-driven currents on an irregular grid", J. Phys. Oceanogr. 10 (1980) 1417-1438.

[11] J. R. Garratt, "Review of drag coefficients over oceans and continents", Mon. Weather Rev. 105 (1977) 915-929.

[12] J. E. Geisler, "Linear theory of the response of a two layer ocean to a moving hurricane", Geo. Phys. Fluid Dyn. 2 (1970) 249-272.

[13] R. J. Greatbatch, "On the response of the ocean to a moving storm: the nonlinear dynamics", $J$. Phys. Oceanogr. 13 (1983) 357-367.

[14] R. J. Greatbatch, "On the response of the ocean to a moving storm: parameters and scales", $J$. Phys. Oceanogr. 14 (1984) 59-78.

[15] N. S. Heaps, "Development of storm-surge models at Bidston", Report No. 53, Institute of Oceanographic Sciences, Bidston Observatory (UK), 1977.

[16] C. J. Hearn and P. E. Holloway, "A three-dimensional barotropic model of the response of the Australian north west shelf to tropical cyclones", J. Phys. Oceanogr. 20 (1990) 60-80.

[17] C. J. Hearn and J. R. Hunter, "Modelling wind-driven flow in shallow systems on the southwest australian coast", Numerical Modelling: Application to Marine Systems (1987) 47-57.

[18] G. J. Holland, "An analytic model of the wind and pressure profiles in hurricanes", Mon. Weather Rev. 108 (1980) 1212-1218.

[19] P. E. Holloway, "Internal tides on the Australian north west shelf: A preliminary investigation", $J$. Phys. Oceanogr. 13 (1983) 1357-1370.

[20] P. E. Holloway, "Tides on the Australian north west shelf", Aust. J. Mar. Fresh. Res. 34 (1983) 213-230.

[21] P. E. Holloway, "On the semi-diurnal internal tide at a shelf-break region on the Australia north west shelf”, J. Phys. Oceanogr. 14 (1984) 1787-1799.

[22] P. E. Holloway, "Internal hydraulic jumps and solitons at a shelf break region on the Australian north west shelf", J. Geophy. Research 92 (1987) 5405-5416.

[23] P. E. Holloway, I. Barnes, I. Webster and J. Imberger, "Dynamics of the north west shelf. Report prepared for Woodside Offshore Petroleum", Centre for Water Research Environmental Dynamics Report ED-81-008, University of Western Australia, 1981.

[24] P. E. Holloway and H. C. Nye, "Observed response of the north-west shelf waters to tropical cyclones: 1979 to 1984”, Centre for Water Research Environmental Dynamics Report ED-84-092, University of Western Australia, 1984.

[25] J. Imberger and P. E. Holloway, "Dynamics of the north west shelf. Progress report and proposal for future studies", Centre for Water Research Environmental Dynamics Report ED-81-006, University of Western Australia, 1981.

[26] C. L. Jordan, "On the influence of tropical cyclones on the sea surface temperature field", Proc. Symp. on Tropical Meteorology, N. Z. (1963) 614-622.

[27] K. Kajiura, "A forced wave caused by atmospheric disturbances in deep water", Technical report 133-1, Dept. of Oceanography and Meteorology, Texas A\&M University, 1956.

[28] H. Kato and O. M. Phillips, "On the penetration of turbulent layer into stratified fluid", J. Fluid Mech. 37 (1969) 643-655.

[29] H.-H. Kuo and T. Ichiye, "A numerical study of the response of barotropic ocean to a moving hurricane", Tellus 29 (1977) 561-571.

[30] K. F. Lovell, B. A. Harper and B. D. Chandler, "Calibration of an analytic model of the wind and pressure profiles in hurricanes", Report to Woodside Offshore Petroleum, 1990. 
[31] R. V. Madala and S. A. Piacsek, "A semi-implicit numerical model for baroclinic oceans", J. Comp. Phys. 23 (1977) 167-178.

[32] P. J. Martin, "Mixed-layer simulation of buoy observations taken during hurricane Eloise", $J$. Geophysic. Res. 87 (1982) 409-427.

[33] W. H. Munk and E. R. Anderson, "Notes on a theory of the thermocline", J. Mar. Res. 7 (1948) 276-295.

[34] J. Noye, "Finite difference methods for solving the 1-D transport equation", in Numerical Modelling: Application to Marine Systems (ed. J. Noye), (1987), 231-256.

[35] J. J. O'Brien, "The non-linear response of a two-layer, baroclinic ocean to a stationary, axiallysymmetric hurricane: Part II. Upwelling and mixing induced by momentum transfer", J. Atmos. Sci. 24 (1967) 208-215.

[36] J. J. O'Brien and R. O. Reid, "The non-linear response of a two-layer, baroclinic ocean to a stationary, axially-symmetric hurricane: Part I. Upwelling induced by momentum transfer", $J$. Atmos. Sci. 24 (1967) 197-207.

[37] J. Pedlosky, Geophysical fluid dynamics (Springer-Verlag, New York, 1979).

[38] R. Peyret and T. D. Taylor, Computational methods for fluid flow (Springer-Verlag, New York, 1982).

[39] R.T. Pollard, P. B. Rhines and R. O. R. Y. Thompson, "The deepening of the wind-mixed layer", Geophys. Fluid Dyn. 3 (1973) 381-404.

[40] J. F. Price, "On the scaling of stress-driven entrainment experiments", J. Fluid Mech. 90 (1979) 509-529.

[41] J. F. Price, "Upper ocean response to a hurricane", J. Phys. Oceanogr. 11 (1981) 153-175.

[42] L. K. Shay, S. W. Chang and R. L. Elsberry, "Free surface effects on the near-inertial ocean current response to a hurricane", J. Phys. Oceanogr. 20 (1990) 1405-1424.

[43] T. J. Simons, "Circulation models of lakes and inland seas", Can. Bull. Fish. Aquat. SCI. 203 (1980) 25 .

[44] G. D. Smith, Numerical solution of partial differential equations, 2nd ed. (Clarendon Press, 1978).

[45] R.H Spigel, J. Imberger and K. N. Rayner, "Modeling the diurnal mixed layer", Limnol. Oceanogr. 32 (1986) 533-556.

[46] N. Suginohara, "Response of a two-layer ocean to typhoon passage in the western boundary region", J. Oceanogr. Soc. in Japan 29 (1973) 10-23.

[47] H. Tennekes, "Turbulent entrainment in stratified fluids", Memoires Societe Royale des Sciences de Liege 6 (1973) 131-139.

[48] I. Webster, "Frictional continental shelf waves and the circulation response of a continental shelf to wind forcing", J. Phys. Oceanogr. 15 (1985) 855-864.

[49] I. Webster, "Wind-driven circulation on the North West Shelf of Australia", J. Phys. Oceanogr. 15 (1985) 1357-1368.

[50] G. W. Withee and A. Johnson, "Buoy observation during hurricane Eloise (September 19 to October 11, 1975)", Data report, U.S. Department of Commerce, NOAA, NSTL Station, Mississippi, 1976.

[51] J. Wu, "Wind-stress coefficients over sea surface near neutral conditions: A revisit", J. Phys. Oceanogr. 10 (1980) 727-740.

[52] J. A. Zelt, "A three-dimensional model of currents and mixing induced by a tropical cyclone on a shelf”, Centre for Water Research Environmental Dynamics Report ED-88-267, University of Western Australia, 1988. 